\title{
Viviendas en renta en ciudades mexicanas
}

\section{Rental housing in Mexican cities}

Jaime Sobrino*

\section{Resumen}

El objetivo de este artículo consiste en estudiar el número, la evolución, las características y la distribución territorial de las viviendas en renta en México y en sus principales ciudades, así como los atributos sociodemográficos de las personas y los hogares que residen en éstas. La pregunta que guía al artículo es la siguiente: ¿cuál ha sido la importancia de la vivienda en renta en la demanda habitacional del país en el periodo 1950-2015, y cómo se ha relacionado la vivienda en renta con los procesos más generales de la ciudad, como la pobreza, la desigualdad y la segregación? Para cumplir con estos propósitos, se utiliza la información sobre tenencia de la vivienda contenida en los censos de población y vivienda de 1950 a 2010 y la Encuesta Intercensal 2015. El análisis se centra en las 95 ciudades con mayor tamaño de población en 2010. Entre los principales hallazgos destaca que el dinamismo de las viviendas en arrendamiento en México no ha sido significativo, en gran medida por la política habitacional instaurada por el Estado mexicano, que ha priorizado la tenencia en propiedad de la vivienda. El mercado de vivienda en renta se circunscribe a ciudades especificas y a ciertas zonas dentro de las ciudades, especialmente edificios y vecindades ubicadas en áreas centrales. La proporción de viviendas en renta se relaciona con la dinámica demográfica de la ciudad, el mayor número de hogares unipersonales, la densidad de población más alta, su especialización en actividades turisticas y la mayor desigualdad social. Existe también una estrecha relación entre el curso de vida de las personas, el ciclo de las familias y el tipo de tenencia en su selección residencial.

* El Colegio de México, A.C., Centro de Estudios Demográficos, Urbanos y Ambientales. Dirección: Carretera Picacho Ajusco, 20, Ampliación Fuentes del Pedregal, 14110, Ciudad de México, México. Correo: 1jsobrin@colmex.mx ORCID: https://orcid.org/0000-0002-27887209

Nota del autor: Agradezco los comentarios recibidos por parte de los dictaminadores a la primera versión de este artículo. 
Palabras clave: ciudad y vivienda; viviendas en renta; desigualdad y segregación; curso de vida y selección residencial.

\begin{abstract}
The purpose of this article is to study the number, evolution, characteristics, and territorial distribution of rental housing in Mexico and its main cities, as well as the sociodemographic attributes of the people and households that reside in them. The question that guides the article is the following: What has been the importance of rental housing in the country's housing demand in the period 1950-2015, and how has rental housing been related to the more general processes of the city, such as poverty, inequality and segregation? To achieve these aims, the information on housing ownership contained in the population and housing censuses from 1950 to 2010 and the Intercensal Survey 2015 is used. The analysis focuses on the 95 cities with the largest population size in 2010. The main findings include the fact that the dynamism of rental housing in Mexico has not been significant, largely due to the housing policy established by the Mexican state, which has prioritized home ownership. The rental housing market is limited to specific cities and certain areas within cities, especially buildings and neighborhoods located in central areas. The proportion of houses for rent is related to the demographic dynamics of the city, the larger number of one-person households, the higher population density, its specialization in tourist activities and greater social inequality. There is also a close relationship between the life course of individuals, the cycle of families and the type of ownership in their residential selection.
\end{abstract}

Keywords: city and housing; rental housing; inequality and segregation; life course and residential selection.

\title{
Introducción
}

La vivienda es un bien que satisface necesidades básicas. Se ha considerado un medio de consumo colectivo al constituir un espacio para la reproducción y sobrevivencia de los seres humanos (Suárez, 2015; Topalov, 1979, pp. 135-160). Sin embargo, su acceso y el derecho a ésta se encuentran limitados por las características propias de este bien: $i$ ) su elevado costo; ii) su inmovilidad; iii) la necesidad de suelo para su edificación, y iv) su gasto constante en conservación y mantenimiento.

La vivienda ocupa alrededor del 50\% de la superficie de una ciudad y es la principal responsable de la división social del espacio y la segregación. El análisis de la pobreza y la desigualdad en la urbe sólo se puede comprender cuando se utilizan indicadores sobre las características de la vivienda y 
los atributos sociodemográficos de las personas y los hogares que residen en ella. Por ejemplo, el Consejo Nacional de Evaluación de la Política de Desarrollo Social (Coneval) hace la estimación de la pobreza multidimensional en México con el uso de seis indicadores de derechos sociales, dos de ellos vinculados a la vivienda: $i$ ) calidad y espacios de la vivienda, y ii) acceso a servicios básicos en la vivienda (Coneval, 2017).

La vivienda es también un mercado urbano en el que se interrelacionan mecanismos de oferta y demanda. La oferta de vivienda tiene que ver con las formas de su producción, los agentes que intervienen en su construcción y los procesos de ocupación del suelo para uso urbano; mientras que la demanda se relaciona con las opciones de acceso y apropiación a ésta por parte de la población, y sus modalidades de ocupación, siendo dos de ellas la propia y la rentada. La vivienda en renta existe por la imposibilidad de las personas y los hogares para acceder a una vivienda en propiedad, fundamentalmente por su alto costo (Blanco, Fretes y Muñoz, 2014); por cuestiones de conveniencia, ante procesos de selección de subóptimos o second best (Aronsson y Mannberg, 2015), o por circunstancias en el curso de vida de las personas y los hogares (ONU-Habitat, 2003).

Las características de la vivienda y su funcionamiento como mercado están regulados por el Estado. Los gobiernos centrales han formulado desde tiempo atrás programas y políticas habitacionales, mientras que los gobiernos locales, en fechas recientes, se han incorporado para garantizar condiciones de vida adecuadas para su población residente, aprovechando las posibilidades existentes y enfrentándose a las limitaciones impuestas por el mercado y la normatividad (Ziccardi y Cravacuore, 2017).

La población total de México en 2000 fue de 97.5 millones de personas y en ese año había 21.5 millones de viviendas particulares habitadas, con lo que el promedio de ocupación era de 4.5 habitantes por vivienda. Para 2015, la población del país se ubicó en 119.5 millones de personas y las viviendas particulares habitadas aumentaron a 31.9 millones, por lo que la ocupación promedio disminuyó a 3.7 habitantes por vivienda. La caída en el tamaño promedio de los habitantes por vivienda se explica por la evolución de la última etapa de la transición demográfica en el país, que se caracteriza por la disminución en las tasas de fecundidad (Anderson, 2015, pp. 49-50). Otro elemento explicativo de la disminución del tamaño promedio de los hogares es la segunda transición demográfica, la cual consiste en el crecimiento diferencial de los distintos tipos de hogares, habiendo menor dinamismo en los nucleares (Lesthaeghe, 2012). La tasa de crecimiento promedio anual de la población durante esos quince años fue de $1.4 \%$, mientras que la de las viviendas fue de $2.7 \%$. La po- 
blación se incrementó en 23\%, mientras que las viviendas lo hicieron en 48 por ciento.

El total de viviendas rentadas en México en 2000 fue de 2.8 millones y en 2015, de 5.1 millones, lo que significó una tasa de crecimiento promedio anual de $4 \%$, ritmo superior al del crecimiento total de las viviendas particulares habitadas, por lo que su participación se elevó de 13\% en 2000 a $16 \%$ en 2015.

El porcentaje de viviendas rentadas en México en 2010 fue de 14\%, valor intermedio con respecto a los países de América Latina y el Caribe (CEPAL, 2018), y significativamente inferior al observado en naciones de África y de Europa (véase Bouillon, 2012, p. 90). La alta proporción de viviendas en renta en Europa es resultado de dos modalidades de política habitacional adoptadas por los gobiernos centrales (Balchin, Isaac y Chen, 2000, pp. 131-133): por un lado, una política de tipo socialdemócrata, impuesta en Dinamarca, Holanda, Noruega y Suecia, consistente en el otorgamiento de subsidios a la producción de vivienda social en renta; por otro lado, una política de corte corporativista, implementada en Alemania, Austria, Francia e Italia, en donde la vivienda privada en renta se ha mantenido como la forma dominante de la oferta en el mercado.

En los países de América Latina y el Caribe, el porcentaje de viviendas en renta en 2010 osciló entre 5\% en Nicaragua hasta 33\% en Colombia (CEPAL, 2018). En todas estas naciones, incluyendo México, existía un amplio margen de diferencia entre el porcentaje de viviendas rentadas en las comunidades rurales (entre 1 y $11 \%$ ) y en las localidades urbanas (de 7 a 40\%). Los valores en México eran 5\% en el mundo rural y 19\% en el urbano. El mercado de vivienda rentada en México, y por lo menos en América Latina, es un asunto de ciudades: del mercado urbano de vivienda (Gráfica 1). La vivienda en renta en América Latina y el Caribe representó en 2010 alrededor del $20 \%$ de la demanda habitacional total. Ésta fue una proporción significativa a pesar de las políticas nacionales de vivienda, que han estado sesgadas hacia la vivienda en propiedad, ya sea estimulando la producción, u ofreciendo créditos y subsidios a la demanda (Blanco, Fretes y Muñoz, 2014).

Con la información de la Gráfica 1 se aprecia la existencia de cuatro grupos de países en América Latina y el Caribe según el porcentaje de viviendas rentadas en áreas urbanas. Un primer conjunto contiene a Colombia y República Dominicana, con porcentajes de viviendas en renta por arriba del $35 \%$. La alta proporción de viviendas en renta en Colombia es producto de la combinación de elementos vinculados con la oferta, la demanda y la política habitacional. Desde el punto de vista de la oferta, 
la política habitacional ha promovido una limitada producción formal de vivienda, la cual se ha dirigido principalmente a la población de ingresos medios y altos, y una baja producción de vivienda de interés social. Desde la perspectiva de la demanda, la población de ingresos medios y bajos ha visto en la vivienda en renta una mejor opción a sus necesidades de habitación, ante la alternativa de la producción informal; esta selección se apoyó en algún momento en un marco normativo con fuerte inclinación hacia el arrendatario (Torres, 2012).

\section{Gráfica 1}

América Latina: porcentaje de viviendas rentadas en países seleccionados según localidades urbanas y rurales, 2010

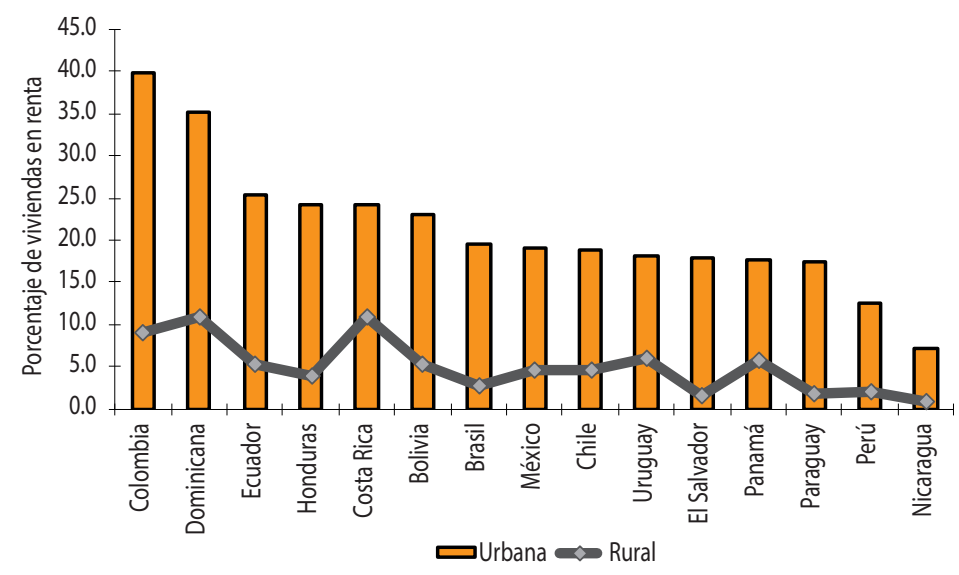

Fuente: Elaboración propia con información de CEPAL, 2018.

En segundo plano se ubican Ecuador, Honduras, Costa Rica y Bolivia, en donde las viviendas en renta en las áreas urbanas representan alrededor de una cuarta parte de las viviendas totales. En el tercer agrupamiento figuran Brasil, México, Chile, Uruguay, El Salvador, Panamá y Paraguay, en donde un poco menos de una quinta parte de las viviendas particulares habitadas son rentadas. Finalmente, en Perú y Nicaragua el mercado urbano de vivienda en renta abarcó menos del 10\%. En el caso de Perú, el bajo porcentaje de viviendas en renta es producto de una política habitacional que, desde la década de 1930, promovió la autoconstrucción en barrios obreros, conocidos como "barriadas", y a lo largo del siglo XX el Estado se abocó a 
mejorar la infraestructura y el equipamiento en estos sectores periféricos de las ciudades (Quispe, 2005).

El porcentaje de viviendas en renta en las localidades urbanas de América Latina y el Caribe mostró en 2010 un efecto decreciente con el nivel de desarrollo: a mayor producto interno bruto por habitante, mayor porcentaje de viviendas en renta, pero dicho porcentaje comenzó a disminuir a partir de un producto por habitante de 7200 dólares.

A partir de estas reflexiones, el propósito de este artículo consiste en analizar las principales características del mercado de vivienda en renta en México, y en especial en sus principales ciudades. Para cumplir con dicho propósito, en el siguiente apartado se presenta una breve revisión bibliográfica sobre la oferta y la demanda de vivienda y sobre la vivienda en renta en México y América Latina. Posteriormente, se revisan las principales fuentes de información para el estudio de la vivienda en renta en México. En el cuarto apartado se ofrece un examen sobre las características y la evolución de las viviendas en renta en las principales ciudades de México en el periodo 1990-2015. El quinto acápite se destina a estudiar las características sociodemográficas de las personas y los hogares que viven en viviendas rentadas en las ciudades del país. En el último rubro se presentan las conclusiones del artículo.

\section{Mercado de vivienda y vivienda en renta}

La producción de vivienda en México se ha llevado a cabo a través de cuatro formas: $i$ ) autoconstrucción; ii) producción por encargo; iii) producción promocional privada, y iv) producción promocional del Estado (Schteingart, 1989, pp. 117-163). De acuerdo con Priscilla Connolly, la autoconstrucción ha sido el principal mecanismo para incrementar el número de viviendas, utilizando preferentemente suelo ejidal y sin la intervención de instrumentos formales de crédito (Connolly, 2006). Para esta misma autora, los asentamientos irregulares representaban más de la mitad de la oferta de vivienda en las ciudades de México (Connolly, 2012, p. 380). Esta estimación fue realizada por el grupo de Sociología Urbana de la Universidad Autónoma Metropolitana, unidad Azcapotzalco.

En el cuestionario ampliado del Censo de Población y Vivienda 2010 se incluyó, por primera vez en la historia censal de México, una pregunta sobre la forma de adquisición de las viviendas propias. Los resultados de esta pregunta muestran que en los municipios rurales el $47 \%$ de las viviendas particulares habitadas se habían autoconstruido, contra $40 \%$ que se 
mandaron construir, y 7\% que se compraron ya hechas. Para las principales ciudades del país, aquellas con 100 mil y más habitantes, los porcentajes fueron significativamente diferentes, puesto que las viviendas autoconstruidas representaron $28 \%$, mientras que las que se compraron ya hechas fueron el $41 \%$, y $27 \%$ se mandaron construir. Según estas cifras, la autoconstrucción de vivienda era asunto preferentemente de las áreas rurales.

La diferencia entre los porcentajes de viviendas autoconstruidas, según el grupo de Sociología Urbana de UAM y los resultados censales, radica en la forma de aproximación. En el primer caso, la estimación se sustenta en la división del espacio urbano según los tipos de poblamiento urbano y el supuesto de que un tipo específico de poblamiento estaría más relacionado con la autoproducción de vivienda (Connolly, 2012, pp. 389-419). En el segundo caso, en el cuestionario ampliado se preguntó en aquellas viviendas de tenencia propia si el dueño o propietario de la vivienda la había comprado hecha, la mandó construir, la construyó él mismo, o la obtuvo de otra manera. Sea cual fuere la forma de estimación, es un hecho el peso relevante de la autoconstrucción de vivienda en las formas de producción habitacional en México. La política habitacional del Estado mexicano ha contribuido a la autoconstrucción de vivienda, puesto que en 1981 creó el ahora Fideicomiso Fondo Nacional de Habitaciones Populares (Fonhapo) con el propósito de financiar la construcción y el mejoramiento de la vivienda por autoconstrucción. Entre 2011 y 2015, el Fonhapo otorgó subsidios para 545 mil unidades de vivienda, frente a 987 mil subsidios que proporcionó la Conavi para unidades de vivienda propia.

Siguiendo con los datos proporcionados por el Censo de Población y Vivienda 2010, el rango de autoconstrucción de viviendas en las principales ciudades del país iba desde menos del 15\% en Mérida, Ciudad Obregón, Los Mochis y Campeche, hasta más del 45\% en Tula, San Luis Río Colorado, Guanajuato, Ciudad Cuauhtémoc y Fresnillo. Con el uso de un modelo de regresión lineal múltiple se concluye que el porcentaje de viviendas autoconstruidas en las principales ciudades no estaba relacionado con el tamaño de población de la urbe, ni con su dinámica de crecimiento poblacional en el periodo 1990-2010, pero sí con la incidencia de pobreza en ella (véase Sobrino, 2014): a mayor porcentaje de población en condición de pobreza, mayor porcentaje de viviendas autoconstruidas.

La producción de vivienda en serie ha atravesado dos momentos desde 1970: el primero transcurrió hasta el año 1993, cuando el Estado fue el principal promotor de esta forma de producción; cabe destacar, por ejemplo, que entre 1971 y 1976 éste se encargó de la producción de alrededor de una quinta parte de la nueva vivienda (Garza y Schteingart, 1978, pp. 227-237). 
El segundo momento se dio a partir de 1994, cuando las agencias privadas se encargaron de la producción, en tanto que el Estado reorientó su actuación hacia el financiamiento y subsidió a la demanda (Patiño, 2006; Puebla, 2006; Olivera, 2018). En otras palabras, el Estado transformó su función habitacional desde aquella orientada a la producción y oferta de vivienda, a la enfocada al fomento de la demanda habitacional. Este tránsito en la política habitacional, desde la promoción de la oferta al fomento a la demanda, fue una constante en las actuaciones urbanas de los gobiernos centrales de América Latina durante los últimos años del siglo XX y los primeros del siglo XXI (Ward, Jiménez y Di Virgilio, 2015).

Las agencias privadas fueron actores clave en la producción formal de vivienda en México durante la primera década del nuevo milenio, a partir de desarrollos habitacionales -que en algunos casos fueron de varios miles de viviendas- localizados en las periferias urbanas de varias ciudades del país y que en muchas ocasiones no contaban con la infraestructura y equipamiento necesarios (Castro, Coulomb, León y Puebla, 2006; Montoya, 2011; Núñez, 2007). El efecto de lo anterior ha sido la generación y acentuación de desbalances entre el crecimiento urbano y la planeación territorial, la desarticulación urbana, el desajuste entre los lugares de trabajo y la residencia, y la menor densidad de población.

El gobierno federal puso en marcha en octubre de 2006 el Registro Único de Vivienda (RUV) con el propósito de producir información sobre la totalidad de la oferta de vivienda usada y en proceso de edificación en el contexto nacional, cuya compra pudiera ser financiada por entidades hipotecarias públicas y privadas. Con base en información de la Comisión Nacional de Vivienda (Conavi, 2019), entre octubre de 2006 y diciembre de 2012 los desarrolladores privados registraron 3.1 millones de viviendas, mientras que de enero de 2013 a noviembre de 2018 la oferta registrada cayó a 1.9 millones de viviendas. Es un hecho que la producción promocional privada disminuyó de manera significativa durante el sexenio de Enrique Peña Nieto en relación con la registrada en los dos sexenios panistas precedentes. Una causa de tal contracción fue la creación de la Secretaría de Desarrollo Agrario, Territorial y Urbano (Sedatu), ministerio que tuvo mayor intervención en la regulación de la producción privada de vivienda.

Por otro lado, en la demanda de vivienda se analiza la forma de consumo, que puede ser en propiedad, alquiler, prestada u otra situación. La propiedad de la vivienda es una buena opción para muchas personas y hogares, pero no para todos. El arrendamiento de una vivienda puede ser mejor opción para aquellas personas y hogares en donde la propiedad de ésta no se ajusta a sus posibilidades, necesidades, estilo de vida o situación en la que 
se encuentran con respecto a las transiciones en el curso de vida (Bouillon, 2012, pp. 87-92).

Las características de la vivienda en alquiler son las siguientes (Coulomb, 2006, pp. 116-121): i) la vivienda en arrendamiento se encuentra principalmente en las ciudades; ii) el alquiler no siempre tiene una expresión estrictamente monetaria; iii) un porcentaje importante de viviendas o cuartos son alquilados fuera de la normatividad vigente; iv) existen viviendas que se arriendan en contra de una disposición vigente, y $v$ ) puede existir un desajuste entre la calidad de la vivienda y su monto de renta. Este último elemento tiene relevancia porque en la vivienda en renta, la localización y los atributos del vecindario son más importantes en la determinación de la renta, mientras que en la vivienda en propiedad, el tamaño y la calidad de la vivienda juegan un papel fundamental en la determinación del precio de la morada (véase Sobrino, 2014a). También se debe tomar en cuenta que el mercado de vivienda en renta se relaciona estrechamente con el mercado de suelo en el que tiene lugar (Salazar, Puebla, Ponce y Flores, 2014).

Los desequilibrios existentes entre la oferta y la demanda de vivienda en la ciudad se resumen de la siguiente manera: $i$ ) desequilibrio estático, en términos del número de viviendas (oferta) en relación con el número de hogares (demanda); ii) dinámico, que muestra el cambio en el número de viviendas frente al cambio en el número de hogares; iii) espacial, desde el punto de vista de la situación oferta-demanda en una ciudad o en una zona de ésta; y $i v)$ cualitativo, en términos de la calidad ofertada frente a la demandada (Balchin, Isaac y Chen, 2000, p. 127). Estos desequilibrios se presentan tanto en la vivienda en propiedad como en la vivienda en renta, y se expresan en dos eventos antagónicos que ocurren en la ciudad al mismo tiempo: $i$ ) sobreoferta de viviendas (desocupadas o abandonadas), y ii) déficit habitacional (por hogares sin vivienda, por deterioro de la vivienda o por hacinamiento de la misma). Estos eventos antagónicos se complementan con dos procesos derivados de la forma espacial que adquiere el mercado de vivienda: $i)$ segregación residencial, o separación espacial de hogares con características similares, y ii) gentrificación, o cambio socioespacial ascendente o descendente que ocurre por la movilidad residencial.

En el caso del mercado de vivienda en renta, un desequilibrio adicional consiste en el control de rentas, mecanismo de política urbana que tiene el propósito de inhibir incrementos en la renta, además de que el monto de ésta no es determinado libremente por el mercado (Moctezuma Mendoza, 2016; von Ommeren y Graaf-de Zijl, 2013). En 1942 se instituyó en la Ciudad de México un decreto de congelación de rentas para mantener sin cambio el monto de la renta de cuartos o viviendas con rentas de hasta 300 pesos en 
ese momento (González, 2006). Este decreto se ratificó de manera indefinida en 1948 y fue abrogado hasta el año 2001. El control de rentas fue uno de los elementos que coadyuvaron al despoblamiento y deterioro físico de la ciudad central de esta urbe (García, 2017; Isunza, 2010).

La política habitacional en México y en América Latina ha privilegiado las acciones enfocadas desde la oferta o la demanda para la propiedad de la vivienda. Sin embargo, una política de vivienda en alquiler con herramientas adecuadas de planeación y ordenamiento territorial puede contribuir a mitigar el crecimiento periférico de baja densidad y la segregación, para dar lugar a ciudades con mayor densidad, accesibles y compactas. También es factible estimular la oferta de vivienda en renta mediante incentivos dirigidos a incorporar al mercado las existencias de vivienda usada y no habitada (Blanco, Fretes y Muñoz, 2014, p. vi). Para el caso de la vivienda nueva en renta, por ejemplo, en México se inició en 2011 la operación de los Fideicomisos de Infraestructura y Bienes Raíces (Fibras), instrumentos destinados al financiamiento para la construcción y adquisición de bienes inmuebles en arrendamiento y para uso comercial, de oficinas, mixto y habitacional. Su financiamiento proviene de títulos públicos a través de certificados en el mercado de valores (CIDOC y SHF, 2014, pp. 50-52). Entre 2011 y 2017 se crearon 12 Fibras y se obtuvieron recursos por 149 mil millones de pesos (Celis, 2017). Sin embargo, ninguna de estas Fibras se había dedicado en exclusiva a la producción de vivienda en renta, por lo que existen aún posibilidades para la diversificación de las operaciones de las Fibras y contribuir a la oferta de vivienda en renta.

Desde el punto de vista de la demanda, una opción de política habitacional para la vivienda en renta consiste en los programas de subsidios a la población de bajos ingresos, lo que tendría incidencia positiva sobre el nivel de ingreso real de los hogares, sus condiciones de habitación y un cierto freno a la urbanización ilegal (ONU-Habitat, 2012, p. 67). En México, el Infonavit cuenta desde 2014 con el programa Arrendavit, que le ofrece a sus afiliados rentar una vivienda por un año para que al finalizar éste, pueda haber una opción de compra. Asimismo, el Programa de Vivienda Social (antes Programa de Acceso al Financiamiento para Soluciones Habitacionales) de la Conavi cuenta con un apoyo para el arrendamiento de vivienda, aunque sólo está dirigido a las personas que se desempeñan en las fuerzas armadas.

Los instrumentos de política del Estado mexicano para la vivienda en renta son limitados, por lo que se deberá avanzar en ellos debido a que, como se verá más adelante, es una opción concreta y viable para determinados grupos de la población urbana. Además, una tarea pendiente en México 
y América Latina consiste en la seguridad jurídica de los arrendatarios, ya que buena parte de la vivienda en renta carece de contrato escrito, cuando se tiene dicho contrato se desconoce la legislación, o también existen casos en que aun conociéndose no se aplica.

Las acciones de política habitacional para la vivienda en renta podrían generar los siguientes beneficios: i) ampliar las opciones del mercado; ii) ofrecer alternativas de política habitacional para reducir el rezago habitacional; iii) mejorar el desempeño económico de la ciudad, y iv) inhibir la urbanización irregular e ilegal (Bouillon, 2012, p. 87).

\section{Evolución de las viviendas en renta}

Los censos de población y vivienda de México ofrecen información amplia y sistemática para estudiar el número, las características y la evolución de las viviendas en el país. En el Tercer Censo de Población de los Estados Unidos Mexicanos, de 1910, se ofrecieron datos sobre el número de casas, moradas colectivas y templos. Las habitaciones se dividieron según el número de pisos, de uno a cinco o más, así como las casas y jacales. En ese año había 3.1 millones de habitaciones, en donde vivían 15.2 millones de personas, con un promedio de ocupación de 4.8 habitantes por casa. En el Quinto Censo de Población, de 1930, se levantó información sobre el número de familias, contabilizándose 3.3 millones, y se registraron 16.3 millones de habitantes, con un promedio de 4.9 personas por familia.

El Séptimo Censo General de Población de 1950 representó un parteaguas en la estadística de México, ya que fue el primer instrumento que recogió información sobre un variado número de características de la población y las viviendas: población, estado civil, migración, educación, lengua indígena, alfabetismo, religión, alimentación y calzado, características económicas, familia censal, vivienda, y fecundidad. Muchos de los tabulados básicos de ese censo se han seguido levantando en los subsiguientes, hasta la última Encuesta Intercensal, de 2015, y los cuestionarios básico y ampliado del Censo de Población y Vivienda 2020. La familia censal se definió como la persona o todas las personas que vivían o residían habitualmente en la casa o en la vivienda.

En el VIII Censo General de Población 1960 se afinó la acepción mexicana de definición de familia censal, siendo ésta el conjunto de personas generalmente vinculadas por parentesco, que hacen vida común bajo un mismo techo y que comparten un mismo gasto en alimentos. Aquellas personas que vivían en la misma vivienda pero que no compartían el gasto en 
alimentos se consideraron como una familia aparte. Este concepto de familia censal permitió identificar y cuantificar el déficit o rezago habitacional de familias sin vivienda por el hecho de habitar dos o más de ellas en una misma vivienda. El rezago habitacional incluye también las viviendas construidas con material perecedero, además de aquellas en donde hay más de dos habitantes por dormitorio.

Los resultados del X Censo General de Población y Vivienda 1980 han sido fuertemente cuestionados por la potencial sobreenumeración que se hizo de la población, y el elevado número y valores porcentuales de las características de la población cuantificadas como no especificadas, en especial los de la población económicamente activa. Sin embargo, fue el primero en añadir en el título la palabra vivienda, además de que ésta fue dividida en particulares y colectivas. Las viviendas particulares se definieron como aquellas destinadas al alojamiento de una familia o de un grupo de personas, aunque en el momento del censo pudieran haberse encontrado en ella dos o más familias o grupos. Por su parte, las viviendas colectivas eran aquellas destinadas a servir como alojamiento especial para un grupo de personas o familiares, sujetas a una subordinación de carácter administrativo, u obligadas a cumplir normas de convivencia por estar relacionadas con un objetivo público o de interés personal común, tales como aspectos de salud, disciplina, enseñanza, religión, trabajo, asistenciales, militares, o de alojamiento.

El Censo de Población y Vivienda 2010 marcó un retroceso para el estudio y la cuantificación del rezago habitacional porque eliminó el concepto de familia y utilizó el de hogar censal, definiéndose como la unidad formada por una o más personas, vinculadas o no por lazos de parentesco, que residen habitualmente en la misma vivienda particular. Con este cambio en la definición de hogar censal, en relación al manejado desde el censo de 1960, prácticamente se equiparó el número de hogares con el número de viviendas. La Encuesta Intercensal 2015 se encargó de borrar la cuantificación del rezago por familias sin vivienda, ya que definió como hogar a la persona o al conjunto de personas que residían habitualmente en una vivienda particular, mientras que la vivienda particular habitada se definió como aquella que en el momento de la entrevista tenía residentes habituales que formaban hogares, incluyendo cualquier recinto, local, refugio, instalación móvil o improvisada, que estuviera habitada. En el diseño del Censo de Población y Vivienda 2020 se mantuvo el precepto de igualar el número de hogares con el número de viviendas particulares habitadas.

La información sobre el número de viviendas particulares habitadas en el país es comparable desde 1980. Por otro lado, sólo es posible realizar la 
cuantificación del rezago habitacional por hogares sin vivienda para el periodo 1960-2000. A partir de 2010, el número de hogares es igual al número de viviendas particulares habitadas, situación que se repite en el diseño de los cuestionarios del Censo de Población y Vivienda 2020.

La tenencia de la vivienda ha sido identificada desde el censo de 1950, pero no hay plena comparabilidad de la información entre los censos porque en cada uno se hizo una pregunta distinta. Así, por ejemplo, en 1950 se les preguntó a los jefes de familia si la casa era propia o alquilada. En 1960 se preguntó si la vivienda era propia o no. Para el IX Censo General de Población 1970 la pregunta fue si la vivienda era propia -aunque no estuviera totalmente pagada- o no. A partir del censo de 1980 la tenencia de la vivienda ha sido captada en un módulo y con batería de preguntas. En ese año se preguntó si la vivienda era propia, aunque estuviera hipotecada o pagándose, rentada o en otra situación. En el XI Censo General de Población y Vivienda 1990 la pregunta fue si la vivienda era propia, rentada o estaba en otra situación. Para el XII Censo General de Población y Vivienda 2000 la pregunta cambió a si la vivienda era propiedad de alguna persona que vivía ahí, o si era rentada, prestada, la cuidaban o se encontraba en otra situación. A los que respondieron que la vivienda era propia se les preguntó si se estaba pagando, estaba totalmente pagada o estaba en otra situación.

Por su parte, en el censo de 2010 la pregunta fue si en esa vivienda vivía el dueño o propietario, si se pagaba renta o si la ocupaban en otra situación. Como se mencionó anteriormente, cuando la respuesta fue que sí vivía el dueño o propietario, entonces se preguntó si éste la había comprado hecha, la mandó construir, la construyó él mismo o la obtuvo de otra manera. Esta segunda pregunta ha permitido dimensionar por primera vez con datos censales el volumen y las características de las viviendas autoconstruidas en México.

En la Encuesta Intercensal 2015 la pregunta sobre tenencia fue si en la vivienda vivía la dueña o el dueño, si se pagaba renta, si era de un familiar o les prestaban la vivienda, o si la ocupaban en otra situación. A las personas que contestaron que sí vivía ahí la dueña o el dueño se les preguntó si la vivienda tenía escrituras; de qué forma había sido adquirida; si había tenido un financiamiento para su adquisición, y si aún tenía una deuda del financiamiento. Por su parte, en el cuestionario ampliado del Censo de Población y Vivienda 2020 se incluye el módulo de tenencia de la vivienda de la misma forma que en la Encuesta Intercensal 2015. Al incluir en dicha encuesta la categoría de si la vivienda era de un familiar, el porcentaje nacional de viviendas propias disminuyó entre 2010 y 2015 de 76 a 68\%, mientras que las que eran de un familiar o prestadas aumentaron de 9 a 16\% (Cuadro 1). 
Con la inclusión de esta categoría se subestima el porcentaje de viviendas propias.

\section{Cuadro 1}

México: viviendas según tenencia, 1950-2015

\begin{tabular}{|c|c|c|c|c|c|}
\hline \multirow[b]{2}{*}{ Año } & \multirow[b]{2}{*}{ Total } & \multicolumn{4}{|c|}{ Tenencia } \\
\hline & & Propia & Rentada & $\begin{array}{l}\text { Prestada o } \\
\text { en otra sit. }\end{array}$ & $\begin{array}{c}\text { No } \\
\text { especificada }\end{array}$ \\
\hline \multicolumn{6}{|c|}{ Miles de viviendas } \\
\hline 1950 & 5259 & 3370 & 1889 & & \\
\hline 1960 & 6409 & 3468 & 2941 & & \\
\hline 1970 & 8286 & 5471 & 2815 & & \\
\hline 1980 & 12074 & 8214 & 2527 & 923 & 410 \\
\hline 1990 & 16035 & 12487 & 2347 & 1099 & 102 \\
\hline 2000 & 21513 & 16836 & 2818 & 1714 & 145 \\
\hline 2010 & 28644 & 21894 & 4018 & 2560 & 172 \\
\hline 2015 & 31924 & 21620 & 5083 & 4985 & 236 \\
\hline \multicolumn{6}{|c|}{ Porcentajes horizontales } \\
\hline 1950 & 100.0 & 64.1 & 35.9 & & \\
\hline 1960 & 100.0 & 54.1 & 45.9 & & \\
\hline 1970 & 100.0 & 66.0 & 34.0 & & \\
\hline 1980 & 100.0 & 68.0 & 20.9 & 7.6 & 3.4 \\
\hline 1990 & 100.0 & 77.9 & 14.6 & 6.9 & 0.6 \\
\hline 2000 & 100.0 & 78.3 & 13.1 & 8.0 & 0.7 \\
\hline 2010 & 100.0 & 76.4 & 14.0 & 8.9 & 0.6 \\
\hline 2015 & 100.0 & 67.7 & 15.9 & 15.6 & 0.7 \\
\hline
\end{tabular}

Fuente: Censo de Población, 1950, 1960 y 1970; Censo General de Población y Vivienda, 1980, 1990, 2000 y 2010; Encuesta Intercensal, 2015.

En el Cuadro 1 se presenta la cuantificación y evolución de las viviendas según cuatro tipos de tenencia de la vivienda en México para el periodo 1950-2015. En un análisis que se hizo sobre la vivienda en renta en México se prefirió utilizar como potencial vivienda en renta toda aquella declarada como de no propiedad (Coulomb, 2006, pp. 115-149). La justificación fue que buena parte de la vivienda declarada como prestada en realidad era rentada, además de que un porcentaje significativo de hogares que habitaban una vivienda alquilada preferían no declarar tal situación. La información 
que se utiliza en este artículo para el estudio de la vivienda en renta es la que aparece en la columna correspondiente. Esto es así porque para esas viviendas se tiene plena certeza de que las personas o los hogares residentes en ellas pagaban una cantidad monetaria por su uso, aunque no se omite el hecho de que alguna proporción de la población no declara correctamente la tenencia de la vivienda en el censo, ni tampoco el que existan personas y hogares que en el arrendamiento de la vivienda no tienen de por medio un pago monetario. Asimismo, la categoría de vivienda prestada estaría más asociada a una modalidad alternativa de vivienda en propiedad y consistente en la ocupación de una vivienda por parte de personas cuyo propietario es algún familiar; esto se corrobora por el significativo cambio de la tenencia prestada o en otra situación entre 2010 y 2015 a raíz del cambio en la formulación de la pregunta sobre tenencia de la vivienda.

La información contenida en el Cuadro 1 permite proponer la existencia de tres etapas en la evolución de la vivienda en México según su tenencia, aunque éstas deben ser tomadas con precaución por la no necesaria comparabilidad de la información en el tiempo. La primera va de 1950 a 1960, cuando las viviendas rentadas elevaron su participación en diez puntos porcentuales para representar $46 \%$ del total en el último año. Durante esta década hubo una importante dinámica en el crecimiento de la población total y urbana, en donde el grado de urbanización avanzó de 28 a 37\%, motivado por la acelerada migración del campo a la ciudad. En 1960 el porcentaje de la población total que vivía en una entidad distinta a la de su nacimiento se ubicó en 14\%. Los inmigrantes que arribaron a las urbes, en especial a la Ciudad de México, se insertaron preferentemente en el mercado de vivienda en renta. En el Distrito Federal el porcentaje de viviendas rentadas se incrementó de $75 \%$ en 1950 a $79 \%$ en 1960 .

La segunda etapa ocurrió entre 1960 y 2000, cuando el porcentaje de viviendas rentadas disminuyó de manera significativa, de 46 a 13\%. En estos cuarenta años hubo grandes cambios demográficos, económicos y de política habitacional. La dinámica demográfica llegó a su clímax y comenzó su disminución por el tránsito a la última etapa del modelo de transición demográfica, caracterizada por la caída en las tasas de fecundidad. La urbanización siguió avanzando hasta llegar a $68 \%$ en 2000 . La migración interna comenzó a perder velocidad, y la intensidad de los migrantes recientes descendió de alrededor de 15 personas por cada mil habitantes al año en la década de 1960, a poco más de siete para el quinquenio 1995-2000.

Desde la perspectiva económica, el gran avance en la proporción de viviendas propias se explica, en parte, por el notable incremento en el ingreso real de los hogares en los años de 1960 a 1980, y posteriormente por la crisis 
de 1980 y el estancamiento en la mejora en las condiciones de vida de la población. La crisis económica ocurrió por el agotamiento del modelo de sustitución de importaciones, el desbalance de las variables macroeconómicas y el abultado déficit presupuestal del gobierno federal. Esto implicaría que, contrario a lo enunciado por la teoría económica espacial (véase Bluestone, Stevenson y Williams, 2008, pp. 401-411; Fujita, 1989, pp. 11-49), los hogares en México ante una disminución en su ingreso real, prefirieron adquirir una vivienda en propiedad que alquilar una vivienda cuya renta se incrementaba por lo menos al ritmo de la inflación, la cual tuvo un crecimiento acumulado entre 1980 y 1990 de $1516 \%$, con un promedio anual de 70 por ciento.

Otro elemento que acompañó al aumento en la proporción de viviendas en propiedad fue la política habitacional. Como se mencionó en el acápite anterior, la política habitacional del gobierno federal en la década de 1970 se distinguió por la producción a gran escala de vivienda para los trabajadores ocupados en la iniciativa privada y los empleados del gobierno federal (Garza y Schteingart, 1978; Patiño, 2006; Puebla, 2006; Schteingart y Graizbord, 1998). Era una política de promoción a la producción y oferta de vivienda. Sin embargo, la crisis económica de los años 1980 y la inserción de México a la etapa del capitalismo global propiciaron un cambio sensible en la política habitacional, en donde el Estado dejó de promover la oferta para fomentar la demanda a través del otorgamiento de créditos y subsidios a la población y a los hogares.

La tercera etapa transcurrió desde el año 2000 y permaneció hasta 2015. Ésta se ha caracterizado por un ligero avance en el porcentaje de viviendas alquiladas, de 13 a $16 \%$. Por su parte, el porcentaje de viviendas en propiedad disminuyó sensiblemente en 2015 a $68 \%$, pero tal contracción se explica porque fue la primera vez que en la pregunta de tenencia se tuvo un rubro específico de respuesta sobre si la vivienda era de un familiar o prestada. Un análisis de minería de datos con los microdatos de la encuesta intercensal permite concluir que los hogares que residían en viviendas prestadas eran predominantemente hogares nucleares en formación con jefatura masculina y cuya edad mediana del jefe de familia era diez años menor que la de los jefes que residían en viviendas propias. Serían hogares que ocupaban una vivienda propiedad de sus padres, situación que en los censos precedentes se ubicaron en la categoría de viviendas en propiedad.

En lo que va del siglo XXI, la tendencia ha sido hacia una ligera menor proporción de viviendas en propiedad, puntos porcentuales que han sido ganados por las viviendas alquiladas. En estos años ha habido un modesto crecimiento económico, nulo avance en el ingreso real de la población, y consolidación de la política habitacional hacia la promoción de la demanda 
vía créditos y subsidios para la adquisición de vivienda. Las condiciones micro y macroeconómicas de estancamiento económico están acordes con la propensión de los hogares a no consumir vivienda en propiedad (véase O'Sullivan, 2009, pp. 358-375). Otro elemento que ha incidido en el incremento en el porcentaje de viviendas alquiladas ha sido el dinamismo de los hogares unipersonales, los cuales duplicaron su participación en los hogares totales del país entre 1990 y 2015 , de 5 a 10 por ciento.

La Encuesta Nacional de Ingresos y Gastos de los Hogares (ENIGH) es otra fuente de información para el estudio de las viviendas en renta en México. Esta encuesta es elaborada por el INEGI cada dos años, realizándose la primera en 1984, y su propósito consiste en generar información sobre la distribución del ingreso y el gasto de los hogares (INEGI, 2018). A partir de la encuesta de 2004 de la serie tradicional se ofrecen datos sobre el número de hogares que realizan un gasto en alquiler bruto de la vivienda, así como el monto de dicho gasto monetario corriente trimestral por deciles de ingreso de los hogares. El número de hogares estimados en 2004 que gastaron en alquiler de vivienda fue de 3.4 millones, lo que representó 13\% del total; tal volumen y porcentaje estarían en consonancia con una interpolación de las viviendas rentadas según las cifras de los censos de 2000 y 2010. Por otro lado, de acuerdo con los resultados de la nueva serie, los hogares con gasto en alquiler bruto en 2016 ascendieron a 4.7 millones y representaron 14\% de los hogares totales, cantidad y porcentaje sensiblemente inferiores a los resultados de la Encuesta Intercensal 2015.

A pesar de las potenciales limitaciones de la información de la ENIGH para el estudio de las viviendas en renta, sobre todo de los datos de 2016, la Gráfica 2 permite identificar la evolución de la propensión a rentar según deciles de ingreso. En 2004, los hogares ubicados en los deciles IV al X tenían mayor propensión a habitar una vivienda en renta, y en especial los de los deciles VI y VII con porcentajes mayores a 16\%. La situación cambió para 2016, en donde los deciles con mayor propensión a ocupar una vivienda arrendada eran del III al VIII, y principalmente los del VII y VIII con porcentajes por arriba del 15\%. Entre 2004 y 2016 los hogares ubicados en los deciles I, II y III aumentaron significativamente su propensión a habitar una vivienda en renta, mientras que los de los deciles VI, IX y X la redujeron. Hay que recordar que este periodo forma parte de la tercera etapa de la evolución de las viviendas en renta en México, identificada con la información del Cuadro 1 y caracterizada por el incremento tendencial en el porcentaje de viviendas rentadas. Una de las causas del aumento en el porcentaje de viviendas en renta fue la mayor demanda a este tipo de tenencia por parte de los hogares ubicados en los estratos de menores ingresos. 


\section{Gráfica 2}

México: gasto en alquiler de vivienda por deciles de hogares, 2004-2016

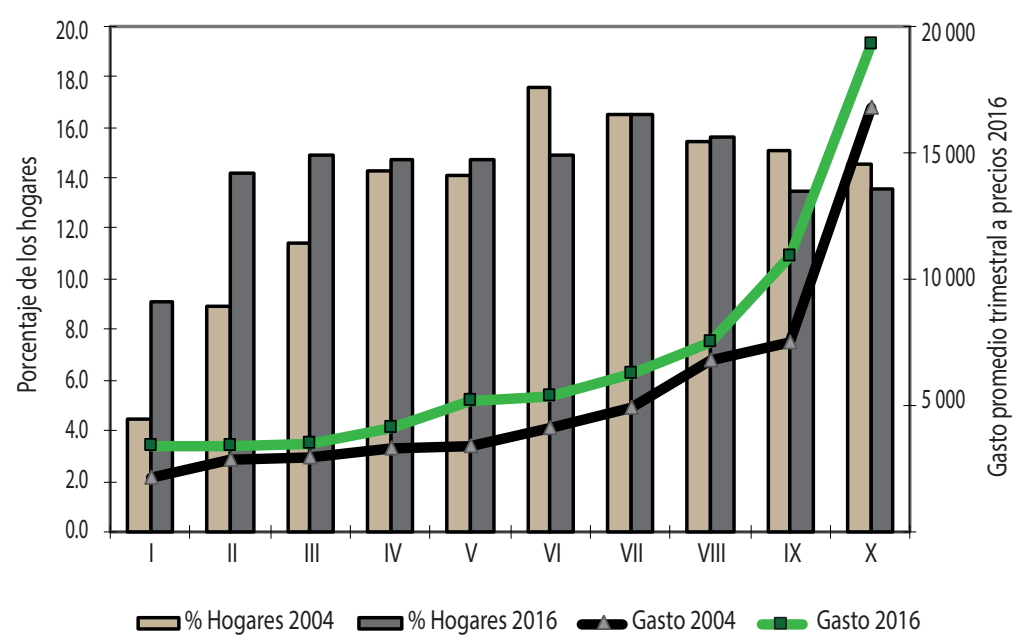

Fuente: Elaboración propia con información de la Encuesta Nacional de Ingresos y Gastos de los Hogares, 2004 y 2016.

Entre 2004 y 2016 el gasto promedio real trimestral en alquiler de vivienda se incrementó en $17 \%$ y tuvo un crecimiento promedio anual de $1.3 \%$, al pasar de 5894 a 6878 pesos, ambos a precios de 2016. Los hogares en los deciles de ingreso I, V y IX experimentaron el mayor incremento en el gasto en alquiler, con porcentajes de alrededor de $50 \%$, mientras que los hogares de los deciles VIII y X tuvieron el menor incremento y con porcentaje de alrededor de $10 \%$. El bajo valor de la tasa de crecimiento promedio anual del pago de renta por la vivienda conduce a pensar que la vivienda en renta no se comportó como un bien escaso, pero sí como un bien inferior (Ferguson y Gould, 1978, pp. 56-69): el ingreso promedio trimestral real de los hogares en el país se contrajo de 33002 pesos en 2004 a 28160 pesos en 2016, a precios constantes de 2016; el gasto promedio en alquiler de vivienda pasó de 5894 a 6878 pesos, por lo que una disminución en el ingreso real se combinó con un aumento en el gasto en consumo de vivienda en renta.

El INEGI levantó en 2014 una encuesta especial en hogares a 29990 viviendas denominada Encuesta Nacional de Vivienda (Envi), y con el apoyo de la Conavi, el Fovissste, el Infonavit y la SHF. Su objetivo consistió en obtener información sobre los gastos y el tiempo de los hogares destinados a 
la autoproducción, autoconstrucción, ampliación, reparación, mantenimiento, remodelación y adquisición de la vivienda principal o segunda vivienda, así como los gastos derivados de su uso (INEGI, 2018a). Para abonar a la discusión sobre la autoconstrucción de vivienda, se tiene que, según datos de esta encuesta, el 35\% de las viviendas particulares habitadas en el país habían sido autoconstruidas, y de ellas el 39\% se habían autoconstruido antes de 1990, 27\% durante la década de 1990, y 33\% de 2000 a 2014. Si se comparan estos porcentajes con el stock total de viviendas en esos momentos, entonces los datos de la encuesta indicarían que la autoconstrucción de vivienda fue particularmente activa durante la década de 1990 y de poca relevancia hasta antes de esos años. No son resultados que concuerden con estudios sobre autoconstrucción de vivienda en México (véase, por ejemplo, Ortega, 2016; Salazar, 2012), por lo que habría que tomar con cautela los resultados de la encuesta sobre este rubro.

Los datos más relevantes de esta encuesta sobre viviendas alquiladas son la ratificación de que éstas eran alrededor del 15\% del total de viviendas particulares habitadas, y que su volumen era parecido al de las viviendas prestadas, valores similares a los reportados en la Encuesta Intercensal 2015. Otro dato fue que el desembolso mensual promedio para reparación y mantenimiento de las viviendas arrendadas fue de 1996 pesos, monto relativamente elevado y que representaría casi $30 \%$ del gasto promedio de renta, según datos de la ENIGH 2016.

\section{Viviendas arrendadas en las principales ciudades de México}

Con base en información del Conapo y la Sedesol, el sistema urbano de México en 2010 estaba conformado con 384 ciudades -todas ellas con población de al menos 15 mil habitantes-, en las que habitaban 81 millones de personas, y el grado de urbanización del país alcanzó 72\% (Conapo y Sedesol, 2012, p. 21). Del total de ciudades, 11 tenían más de un millón de habitantes y 84 contaban con población entre 100 mil y 999 mil habitantes. Estas 95 aglomeraciones urbanas se retoman en este artículo y se les denomina principales ciudades del país. El propio Conapo y la Sedatu elaboraron una actualización del sistema urbano de México al año 2018, a partir de las estimaciones de población por localidad, ciudad y zona metropolitana para ese año, en donde se identifican 401 ciudades habitadas por 93 millones de personas y un grado de urbanización de $74 \%$. Del total de ciudades en ese año, 101 tienen una población estimada de 100 mil y más habitantes, además de que las zonas metropolitanas se incrementan de 59 a 74 debido 
a un cambio sustancial y poco afortunado en los criterios para su delimitación (Sedatu y Conapo, 2018). No es el propósito aquí polemizar sobre estos resultados; será mejor esperar a los resultados del Censo de Población y Vivienda de 2020 para poder corroborar sobre la evolución urbana y metropolitana de México durante la segunda década del nuevo milenio. Lo que sí es un hecho es que una zona metropolitana es aquella área urbana que ocupa suelo de dos o más unidades político-administrativas distintas; no es un área que por alguna razón se le dé un carácter prioritario o estratégico.

En las 95 aglomeraciones urbanas definidas en 2010 con población de 100 mil y más habitantes se incluyen 59 zonas metropolitanas, así como áreas urbanas que se ubican en divisiones político-administrativas menores contiguas y que si bien no están físicamente unidas, lo son en términos funcionales a partir de la movilidad cotidiana por motivo de trabajo (Sedesol, Conapo e INEGI, 2012). El total de los municipios que contenían a las 59 zonas metropolitanas más los de las 36 áreas urbanas no metropolitanas era de 403. Su población conjunta ascendía a 74 millones de personas en 2010, participando con $66 \%$ de la población total nacional. El análisis sobre ciudades y viviendas en renta se lleva a cabo utilizando información de estos 403 municipios.

La vivienda en renta en México es asunto predominantemente urbano y se observa preferentemente en las principales ciudades. En el Cuadro 2 se aprecia que en 2015 el porcentaje de viviendas en alquiler en la Ciudad de México y en el conjunto de metrópolis millonarias era ligeramente mayor a $20 \%$, mientras que en las pequeñas ciudades era de $13 \%$, y de $5 \%$ en las comunidades rurales.

En la Gráfica 3 se presentan las ciudades seleccionadas según su porcentaje de viviendas en renta en 2015. El rango de variación fue desde 7\% en Navojoa a 49\% en Playa del Carmen. Esta última, junto con Puerto Vallarta y Cancún, se ubicaron entre las cinco principales ciudades del país con mayor porcentaje de viviendas en renta, siendo puertos turísticos que, además, tuvieron significativo crecimiento poblacional, por lo que habría aparente relación entre la especialización económica en turismo y el porcentaje de viviendas alquiladas, así como entre la dinámica demográfica, la atracción de población y el porcentaje de viviendas alquiladas.

Por ejemplo, Playa del Carmen incrementó su población de 44 mil personas en 2000 a 192 mil en 2015, con una tasa de crecimiento promedio anual de $10 \%$, mientras que el porcentaje de viviendas arrendadas se incrementó de 37 a 49\% para esos mismos años; el desarrollo de la ciudad ocurrió ante un dinámico mercado de vivienda en renta. Otras metrópolis con importante dinamismo poblacional amparado en la localización industrial, 


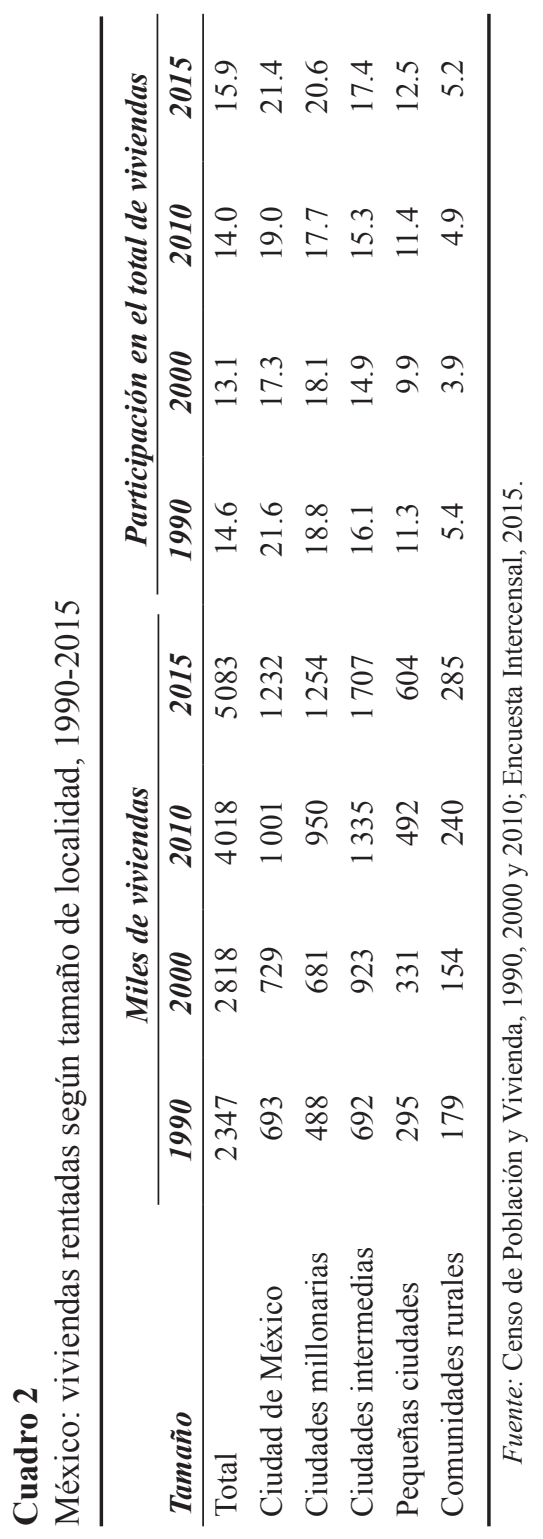


como Saltillo y San Luis Potosí, no tuvieron cambio en la participación de las viviendas en renta entre 2000 y 2015, mientras que en León y Querétaro, también con importante dinamismo por la localización industrial, las viviendas en renta avanzaron discretamente de 15 a 20 por ciento.

\section{Gráfica 3}

México: porcentaje de viviendas en renta en ciudades seleccionadas, 2015

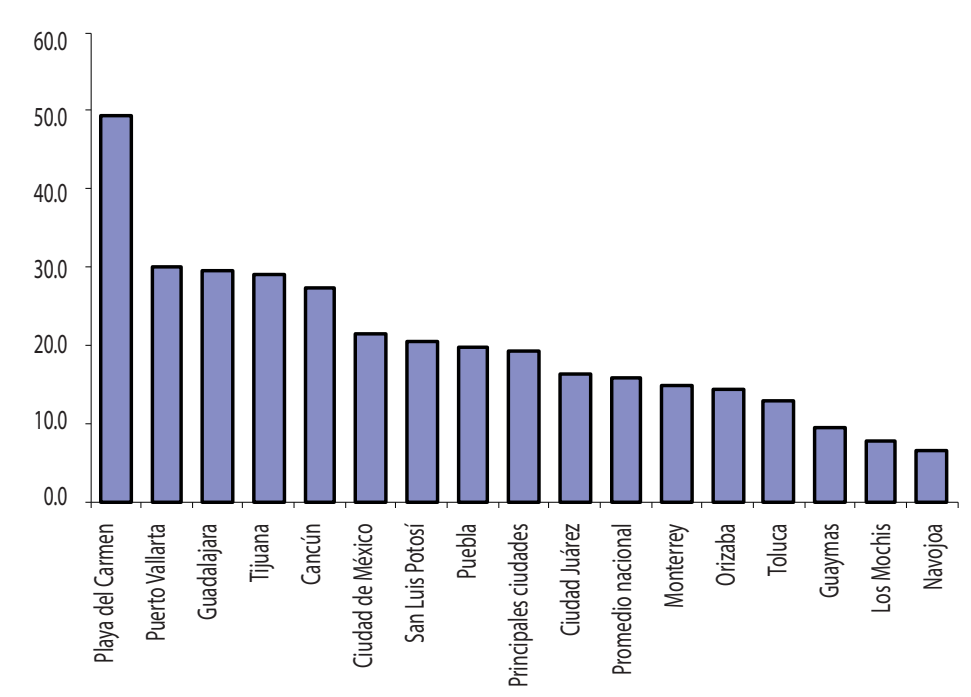

Fuente: Cálculos elaborados con información de la Encuesta Intercensal, 2015.

En el Cuadro 3 se presentan los coeficientes de regresión de los ejercicios realizados, así como aquellos que fueron estadísticamente significativos a un nivel de 0.05 . El modelo 1 incluyó a las 13 variables independientes de estudio (modelo saturado). Éstas no tuvieron problemas de colinealidad y en conjunto explicaron el 54\% de las variaciones de la variable dependiente. Las variables estadísticamente significativas fueron dos de la categoría demográfica: tasa de crecimiento poblacional y densidad de población. Las ciudades con mayor arribo de inmigrantes, y con ello mayor crecimiento poblacional, fueron atractivas para el mercado de vivienda en renta. Asimismo, las ciudades compactas tenían mayor proporción de viviendas en renta.

El modelo 2 es un ejercicio de regresión lineal múltiple bajo el principio de pasos sucesivos hacia adelante (modelo stepwise), que consiste en 
iniciar con un modelo vacío e ir introduciendo en cada iteracción una variable cuyo nivel de significancia sea al menos 0.05 ; este instrumento arroja las variables de mejor ajuste estadístico. Los resultados muestran que a las dos variables de la categoría demográfica -dinámica demográfica y densidad de población-, se añadió una de la categoría económica: población ocupada en actividades turísticas. Estas tres variables explicaron el 50\% de las variaciones de la variable dependiente. Las ciudades con mayor porcentaje de viviendas en renta son también aquellas especializadas en la actividad turística.

\section{Cuadro 3}

Relación entre porcentaje de viviendas

rentadas y atributos de las ciudades, 2015

\begin{tabular}{lccc}
\hline & Modelo & Modelo & Modelo \\
\cline { 2 - 4 } Variables $^{a}$ & $\mathbf{1}$ & $\mathbf{2}$ & $\mathbf{3}$ \\
\hline ln_pob15 & -0.529 & & \\
tcpa_00-15 & $1.874^{* *}$ & $1.782^{* *}$ & \\
densidad_10 & $0.107^{* *}$ & $0.083^{* *}$ & \\
pobreza_10 & -0.010 & & $-0.172^{* *}$ \\
desigualdad_10 & 0.226 & & $0.809^{* *}$ \\
segregación_10 & 0.103 & & $0.260^{* *}$ \\
autoconstrucción_10 & 0.034 & & 0.063 \\
industria_13 & -0.001 & & \\
turismo_13 & 0.229 & $0.267^{* *}$ & \\
desajuste_10 & -0.071 & & \\
capital estatal & -0.806 & & \\
región frontera norte & 1.349 & & \\
región centro & -0.114 & & \\
constante & -1.272 & $5.556^{* *}$ & $-25.491^{* *}$ \\
& & & \\
$\mathrm{R}^{2}$ & 0.539 & 0.495 & 0.167 \\
F & 7.29 & 29.72 & 4.52 \\
\hline
\end{tabular}

${ }^{a}$ La variable dependiente es el porcentaje de viviendas rentadas.

** Coeficientes significativos a un nivel de 0.05 .

Fuente: Elaboración propia. 
Por último, en el modelo 3 se utilizaron únicamente las variables de la categoría social y los resultados son de interés. Las variaciones de estas cuatro variables contribuyeron para explicar el 17\% de las variaciones de la variable dependiente. Pero a pesar de su bajo poder explicativo, tres de ellas fueron estadísticamente significativas: a menor incidencia de pobreza, mayor porcentaje de viviendas rentadas, relación que obliga a pensar que el mercado de vivienda en renta constituye una opción de ingreso para los propietarios de los inmuebles. Asimismo, a mayor porcentaje de vivienda en renta, mayores niveles de desigualdad social y de segregación. Las ciudades con mayor desigualdad y con mayor segregación contienen un porcentaje más alto de viviendas en arrendamiento.

Los microdatos de la Encuesta Intercensal 2015 proporcionan información no sólo del número de viviendas en renta en el país por entidades federativas y municipios, sino también las características de tales viviendas (Cuadro 4). En 2015, del total de viviendas en el país, 16\% estaban arrendadas, y ese porcentaje se elevó a 19\% en el conjunto de las principales ciudades. Ya se había comentado que Playa del Carmen tenía el mayor porcentaje de viviendas rentadas con $49 \%$, mientras que Navojoa el menor con $7 \%$. La proporción de viviendas rentadas en la primera era siete veces mayor con respecto a la segunda.

Los departamentos en edificio son una clase de vivienda en México con mayor uso relativo para su arrendamiento. En 2015 había 1.6 millones de departamentos en el país, de los cuales $43 \%$ estaban rentados. Sin embargo, esta clase de vivienda ha mostrado un dinamismo discreto, ya que su volumen en 2000 era de 1.3 millones, representando $6 \%$ de las viviendas particulares habitadas del país, mientras que los 1.6 millones de departamentos en 2015 equivalían a 5\% de las viviendas particulares habitadas de ese año. El magro dinamismo en el número de departamentos se explica, desde el punto de vista de la oferta, por la política habitacional del Estado mexicano, que ha promovido la producción y adquisición de casas particulares en propiedad en detrimento de otras clases de vivienda, como la de los departamentos, que podría coadyuvar a la densificación urbana y a una menor demanda de suelo. Por el lado de la demanda, es consecuencia de la baja preferencia de los hogares mexicanos al consumo y uso de departamentos en prácticamente todo el país.

Las ciudades con mayor proporción de departamentos en 2015 con relación a sus viviendas particulares habitadas eran: Ciudad de México con $17 \%$, Puerto Vallarta con 9.7\%, Puebla con 9.5\%, Cancún con 9.4\%, Villahermosa con $8.5 \%$, Guadalajara con $8.4 \%$ y Acapulco con $7.2 \%$. En el polo opuesto, Acayucan, Saltillo, Parral, San Luis Río Colorado, Ciudad 
Juárez, Piedras Negras y Tecomán tenían menos de $0.3 \%$ de departamentos, y en Delicias no había uno solo contabilizado.

La Encuesta Intercensal 2015 ofrece dos variables que permiten valorar el tamaño promedio de las viviendas: número de dormitorios y número de focos. Para ese año, el número promedio de dormitorios por vivienda en el país era de 2.0 y de 6.9 el de focos. Entre 2000 y 2015, el tamaño promedio de las viviendas en el país se mantuvo inalterable, es decir, un promedio de 2.0 dormitorios por vivienda. Por otro lado, las viviendas rentadas en 2015 tenían un tamaño promedio de 1.8 dormitorios y 6.4 focos. Las viviendas arrendadas eran en promedio de menor tamaño en relación al total de viviendas en el país. Las ciudades con el mayor tamaño promedio de sus viviendas arrendadas eran: Guanajuato, Zacatecas, Guadalajara, Irapuato, San Luis Potosí y Morelia, todas con promedio mayor a 2.0 dormitorios por vivienda; mientras que las viviendas arrendadas de menor dimensión estaban en: Los Cabos, Cancún, Salina Cruz, Acayucan, Tuxtepec y Playa del Carmen, con promedio menor a 1.5 dormitorios por vivienda. Playa del Carmen era la ciudad con mayor porcentaje de viviendas arrendadas en el país y éstas tenían en promedio 1.3 dormitorios y 4.4 focos. La elevada inmigración a la urbe significó una oportunidad para las personas y para el mercado inmobiliario de ofrecer viviendas de pequeña superficie en arrendamiento a jóvenes de ambos sexos que arribaban a la ciudad. Esta población migrante, al tener una oferta amplia de viviendas en arrendamiento, pero de pequeño tamaño, observa una alta tasa de movilidad residencial intraurbana.

La distribución intrametropolitana de las viviendas en renta muestra un patrón definido y caracterizado por su mayor concentración hacia la ciudad central y en menor medida al primer contorno. Esta concentración de las viviendas en renta en las áreas centrales de las ciudades y zonas metropolitanas es un elemento que explica la relación del porcentaje de viviendas en renta con los patrones de segregación residencial. En el Cuadro 4 se muestra que las viviendas rentadas representan $16 \%$ de las viviendas totales del país y 19\% del total de viviendas en las principales ciudades en 2015. La cuantificación de las viviendas rentadas en la ciudad central se realizó para las zonas metropolitanas delimitadas con dos o más municipios, identificándose como ciudad central al municipio en donde se originó la concentración de población. ${ }^{1}$ Ciudad de México, Puerto Vallarta, Guadalajara y Tijuana tenían el mayor porcentaje de viviendas arrendadas en su ciudad central, y en todas ellas con un valor de $30 \%$ o más.

${ }^{1}$ Para la Ciudad de México, las alcaldías consideradas como ciudad central fueron Benito Juárez, Cuauhtémoc, Miguel Hidalgo y Venustiano Carranza. 


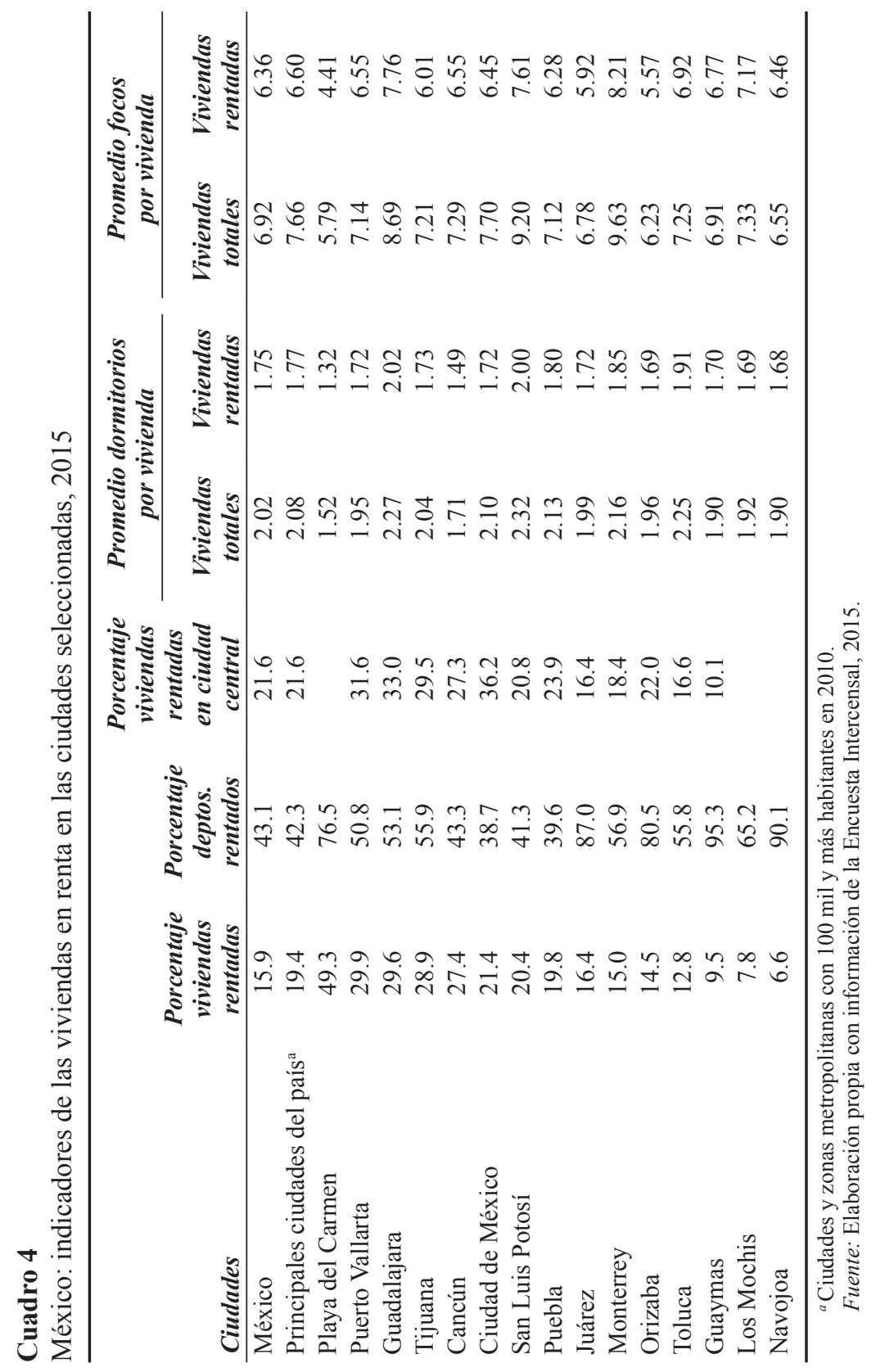


En el Mapa 1 se representa el porcentaje de viviendas en renta por cada división administrativa menor, las cuales conformaban a las principales zonas metropolitanas del país en 2010. En el caso de la Ciudad de México, las alcaldías Benito Juárez, Cuauhtémoc y Miguel Hidalgo, integrantes de la ciudad central de esta metrópoli, tenían en 2015 el 36\% de sus viviendas en renta, mientras que la participación de las viviendas en renta en el stock de viviendas de la megaurbe era de $21 \%$. En Guadalajara, su municipio central tenía 33\% de viviendas en renta, frente a $30 \%$ de toda la zona metropolitana. Igual situación sucedía en los municipios centrales de Monterrey, 18\%, y Puebla, 24\%, frente al total de viviendas en renta en sus zonas metropolitanas: 15 y $20 \%$, respectivamente.

El mayor porcentaje de viviendas arrendadas en la ciudad central en relación al total metropolitano se explica por elementos de la oferta y la demanda del mercado de vivienda. Desde el punto de vista de la oferta, en la ciudad central se concentran los edificios y vecindades que potencialmente ofrecen viviendas en renta, así como casas de tamaño mayor al promedio metropolitano, y una parte de éstas se ofrece al arrendamiento. Desde la perspectiva de la demanda, arrendar una vivienda en la ciudad central es una opción atractiva debido a la accesibilidad que proporciona esa localización y a la diversidad de opciones para la selección de la vivienda a habitar.

\section{Atributos sociodemográficos de las personas y los hogares}

Las personas y los hogares que viven en una vivienda arrendada constituyen un subgrupo específico de la población (Cuadro 5). Los hogares son de menor tamaño en relación al promedio total, mientras que la edad promedio del jefe de hogar es menor. Hay una mayor proporción de hogares unipersonales que viven en moradas arrendadas, mientras que el ingreso promedio de los hogares que rentan una vivienda es mayor con respecto al promedio del total de hogares. No hay diferencias significativas entre los hogares totales y los arrendados desde el punto de vista del sexo del jefe de hogar, así como de la participación de los hogares nucleares.

El atributo sociodemográfico con mayor diferenciación entre los hogares totales y los hogares que residen en una vivienda arrendada en 2015 era la edad promedio del jefe de hogar. En México, éstos tenían una edad promedio de 48 años, mientras que los que encabezaban un hogar en una vivienda rentada tenían 40 años, es decir ocho años menos. La vivienda es una mercancía con alto costo (O'Sullivan, 2009, p. 339), y la adquisición y mudanza a una vivienda en propiedad constituye una de las principales 
transiciones en el curso de vida de las personas y los hogares (Rossi, 1955; Solís, 2016).

\section{Mapa 1}

México: porcentaje de viviendas rentadas en municipios metropolitanos, 2015

\section{Ciudad de México}

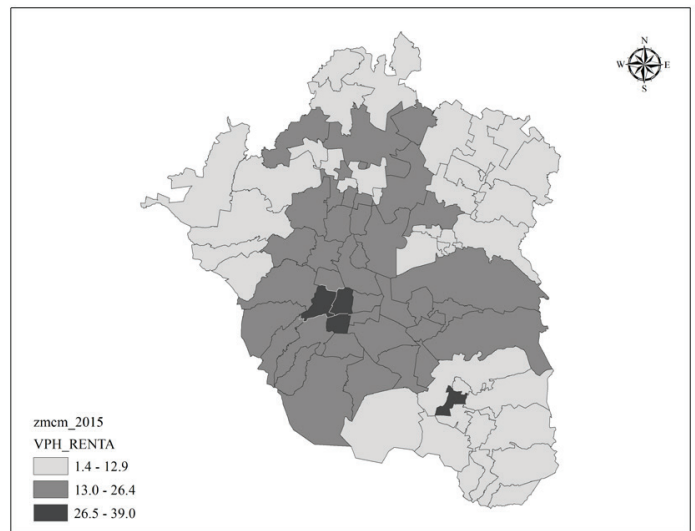

\section{Monterrey}

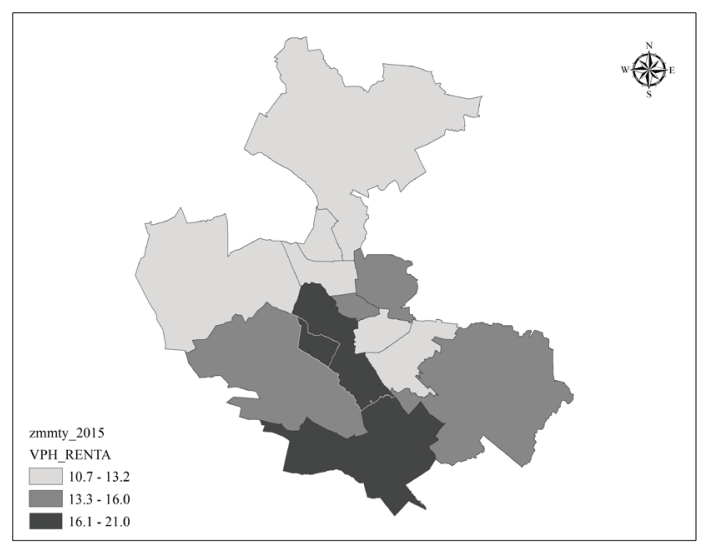

(continúa)

Estudios Demográficos y Urbanos, vol. 36, núm. 1 (106), enero-abril, 2021, pp. 9-48 http://dx.doi.org/10.24201/edu.v36i1.1923 


\section{Mapa 1}

(concluye)

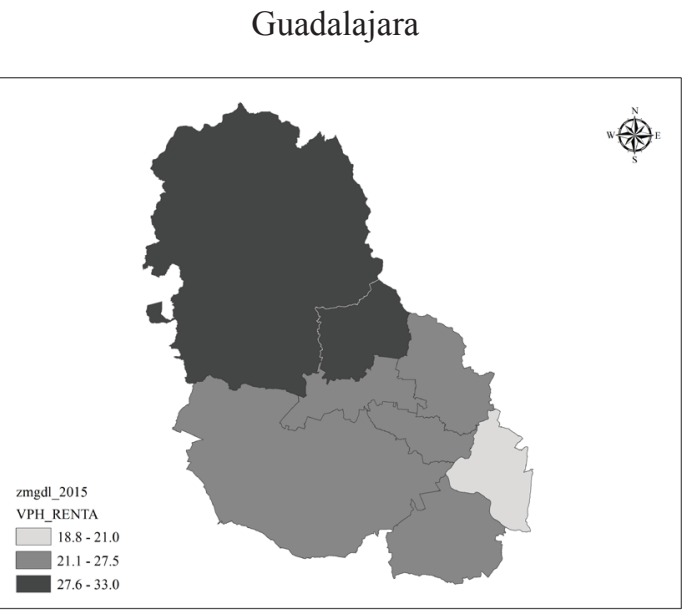

\section{Puebla}

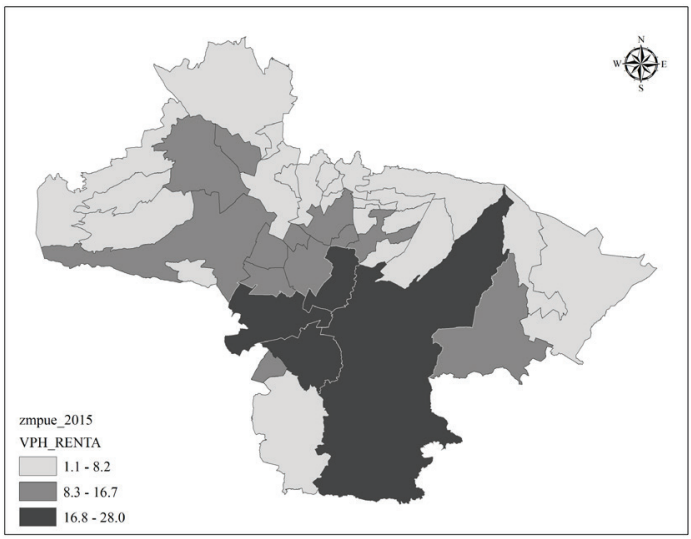

Fuente: Elaboración propia con información de la Encuesta Intercensal, 2015. 


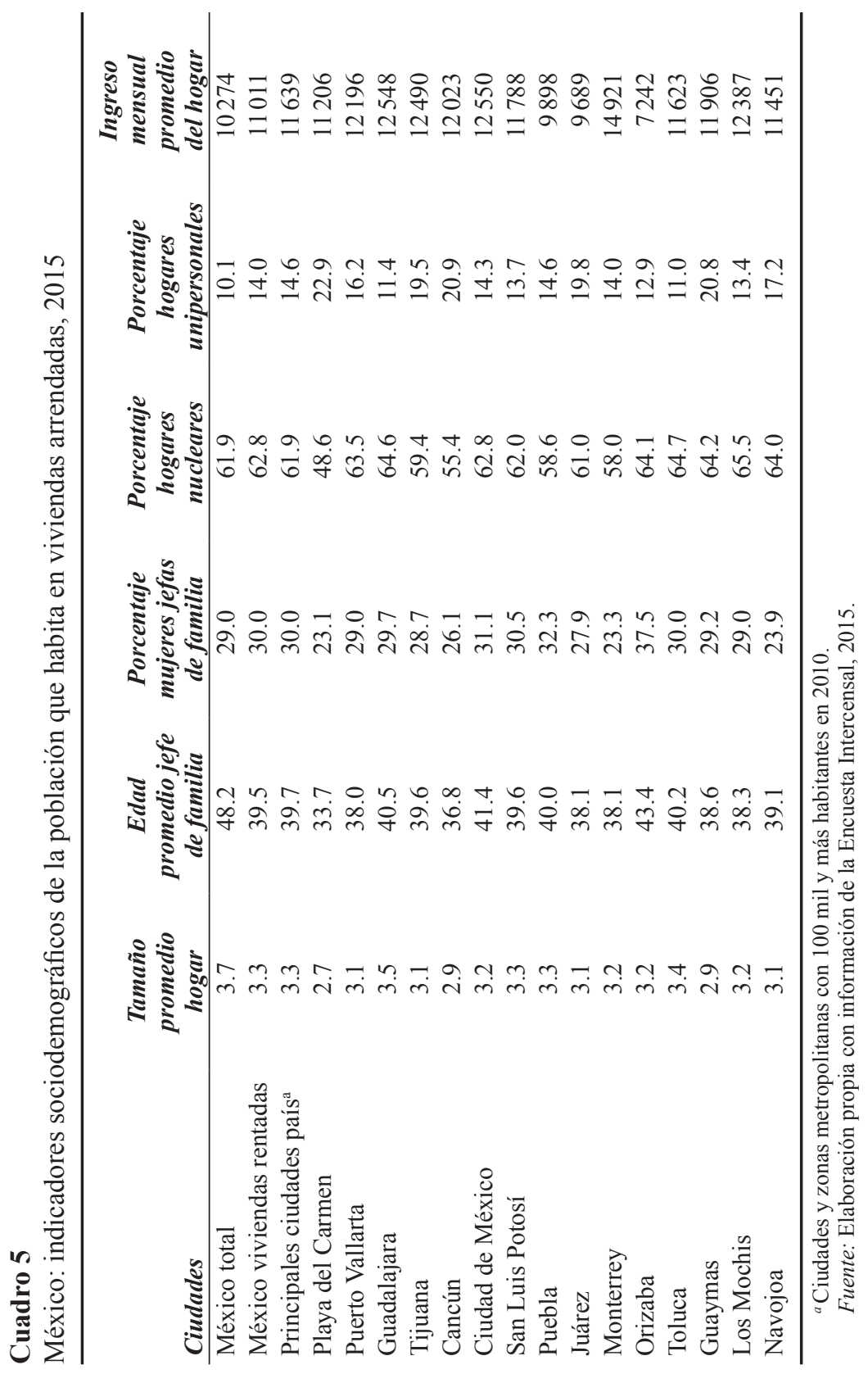


En la Gráfica 4 se muestra el porcentaje de viviendas rentadas según la edad del jefe de hogar en 2015. La tendencia es similar para las mujeres y para los hombres en términos de prevalencia y velocidad. En ambos, la proporción de hogares en viviendas arrendadas aumenta de manera importante entre los 12 y los 19 años, siendo esta última la edad a la que se alcanza la mayor prevalencia, y con valores de $51 \%$ para las mujeres y $42 \%$ para los hombres. A partir de los 19 años y hasta los 40 en hombres y 45 en mujeres, la pendiente disminuye de manera significativa hasta porcentajes de $17 \mathrm{y}$ $18 \%$, respectivamente.

\section{Gráfica 4}

México: edad del jefe de hogar en viviendas arrendadas, 2015

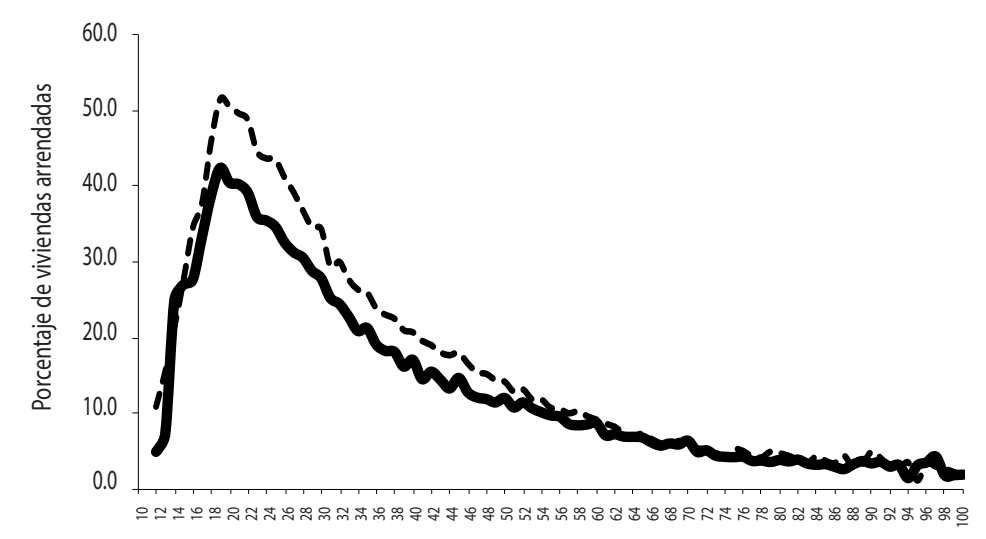

Edad del jefe de hogar

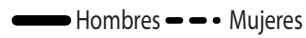

Fuente: Elaboración propia con información de los microdatos de la Encuesta Intercensal, 2015.

Si bien la tendencia es similar entre hombres y mujeres, las diferencias en las proporciones son significativas y ponen de manifiesto la mayor propensión de los hogares con jefatura femenina a habitar una vivienda rentada en relación a un hogar con jefatura masculina. Quizá la diferencia no sea por una mayor preferencia de ellas a vivir en una vivienda rentada, sino por su menor posibilidad para adquirir una vivienda. Este acceso diferencial se puede explicar, en parte, por la brecha de género que existe en el mercado 
de trabajo. En 2015 el ingreso promedio de las mujeres de 19 a 45 años era de 5831 pesos contra 6786 pesos de los hombres, lo que significa una diferencia de $16 \%$. En el contexto nacional había $29 \%$ de hogares con jefatura femenina y $30 \%$ con jefatura femenina que habitaban una vivienda arrendada. Los porcentajes son muy parecidos, pero en cambio el periodo de transición en el curso de vida de los hogares con jefatura femenina para mudarse a una vivienda propia es de mayor duración con respecto al de aquellos con jefatura masculina. La brecha de género en el ingreso y la mayor prevalencia de las jefas de familia en viviendas arrendadas constituyen elementos que coadyuvan a la mayor desigualdad social.

En 2015 uno de cada diez hogares en México era de tipo unipersonal, y éstos se caracterizaban por estar sobrerrepresentados en los grupos de edad de 12 a 22 años y de 58 años en adelante; quizá se trataba de jóvenes que abandonaban el hogar nuclear, por un lado, y de personas que enviudaban, por otro. Por su parte, los hogares unipersonales en viviendas rentadas representaban $14 \%$, y su sobrerrepresentación cubría también los grupos de edad de 12 a 22 años, pero además a los de 50 años en adelante; esto significa que no sólo incluían a jóvenes que dejaban al hogar nuclear y a personas viudas, sino también a quienes estaban en rompimiento de su unión familiar (véase Pérez Amador, 2016).

Estos tres grupos de hogares unipersonales en viviendas rentadas (jóvenes, separados y viudos) tenían distinta distribución geográfica. En las ciudades de Oaxaca, Campeche, Cancún, Puebla y Playa del Carmen había mayor presencia de jóvenes que vivían solos en viviendas rentadas, mientras que las personas solas potencialmente recién separadas o desunidas se encontraban principalmente en San Luis Río Colorado, Irapuato, Iguala, Aguascalientes y Saltillo. Por su parte, en Orizaba, Torreón, Cuernavaca, Guadalajara y Ciudad de México había una proporción más allá de lo esperado de personas solas en vivienda en renta y con edades de 65 años y más.

\section{Conclusiones}

El mercado de vivienda en renta en México se caracteriza por estar concentrado en las ciudades, en las áreas centrales dentro de ellas, con personas que viven solas y en hogares de reciente creación. El ingreso promedio de los hogares que rentan una vivienda es mayor que el de los hogares totales. Existe mayor proporción de viviendas en renta en ciudades con mayor crecimiento poblacional, más compactas y especializadas en actividades turís- 
ticas. Del mismo modo, a mayor desigualdad social y mayor segregación residencial, mayor porcentaje de viviendas rentadas.

La evolución de la vivienda en renta en México a partir de la segunda mitad del siglo XX muestra tres momentos diferentes: el primero ocurrió entre 1950 y 1960, en donde la proporción de viviendas en arrendamiento aumentó significativamente; tal dinamismo estuvo enmarcado en un importante crecimiento demográfico, elevada migración campo-ciudad y escasa participación del Estado en la producción habitacional. La segunda etapa fue de 1960 a 2000, cuando el porcentaje de viviendas arrendadas disminuyó de manera importante y la vivienda en propiedad se consolidó como la tenencia mayoritaria de los hogares del país. En las décadas de 1960 y 1970 hubo un crecimiento en el ingreso real de las personas y los hogares, lo que estimuló la adquisición de vivienda. Otro elemento fue la activa participación del Estado en la producción de vivienda, en especial durante los años de 1970. Para las décadas de 1980 y 1990 el ingreso real de las personas y los hogares mostró reversión y estancamiento, mientras que el Estado produjo menos vivienda y fomentó el consumo de ésta con créditos y subsidios. La vivienda fue vista como una opción para la acumulación del exiguo ingreso ante un escenario de crisis económica.

Por último, entre 2000 y 2015 transita la tercera etapa en donde se observa un ligero incremento en el porcentaje de viviendas en renta, ante el escenario de estancamiento en el ingreso real de la población y una producción habitacional promovida principalmente por la iniciativa privada y con el apoyo del Estado para el otorgamiento de créditos y subsidios para el consumo. Los nuevos hogares han enfrentado mayores dificultades para el acceso a una vivienda en propiedad, y en especial los de menores ingresos. Otro elemento que ha estimulado el incremento de la proporción de las viviendas en renta consiste en el mayor dinamismo de los hogares unipersonales y su propensión a vivir en viviendas rentadas. El notable crecimiento de los hogares unipersonales se debe a la combinación de población joven que deja el hogar de los padres, personas en desunión y sujetos que enviudan.

El mercado de vivienda en renta se presenta preferentemente en las áreas centrales de las ciudades, en donde las personas y los hogares arriendan casas particulares en mayor volumen, pero también departamentos y cuartos en mayor intensidad. Estas áreas centrales contienen viviendas de mayor antigüedad promedio, pero en cambio ofrecen una inmejorable accesibilidad. La concentración de la vivienda en renta en las áreas centrales de la ciudad coadyuva a los patrones de segregación residencial. 
La población que vive en una vivienda arrendada constituye un subgrupo específico caracterizado por hogares de menor tamaño promedio, mayor ingreso y en donde el jefe de hogar tiene menor edad en relación al total de ellos. La vivienda en renta se acompaña con las transiciones en el curso de vida de las personas, consistentes en la salida del hogar nuclear, la formación de un primer hogar, la desunión y la viudez. Asimismo, las mujeres jefas de hogar tienen menor posibilidad de adquirir una vivienda en propiedad en relación con los jefes de hogar debido a las inequidades en las oportunidades laborales. El funcionamiento de los mercados urbanos de trabajo y de vivienda contribuye a la creación, ampliación y mantenimiento de las desigualdades sociales.

Todas estas características ponen de manifiesto la importancia de la vivienda en renta para el mejor funcionamiento de los mercados urbanos de vivienda en el país. Es aconsejable que la política habitacional de México tome en cuenta este submercado, como se hace en otras naciones, lo que permitiría ampliar las opciones del mercado, ofrecer alternativas para grupos de población específicos, intentar reducir la brecha de género entre hogares con respecto al consumo de vivienda, reducir el déficit habitacional y mejorar la economía y el bienestar de las ciudades de México. Esta política habitacional de promoción a la vivienda en renta debe estar enfocada principalmente a grupos y hogares de menores ingresos, así como a personas que viven solas; debe ser una política selectiva y asertiva para mitigar la tendencia a una mayor desigualdad social.

\section{Bibliografía}

Anderson, B. (2015). World population dynamics. Boston, MA: Pearson. Aronsson, T. y Mannberg, A. (2015). Relative consumption of housing: Marginal saving subsidies and income taxes as a second-best policy? Journal of Economic Behavior and Organization, 116, 439-450. Recuperado de https://www.sciencedirect.com/science/article/pii/S0167268115001468

Balchin, P., Isaac, D. y Chen, J. (2000). Urban economics. A global perspective, Houndmills, Inglaterra: Palgrave.

Blanco, A., Fretes, V. y Muñoz, A. (2014). Se busca vivienda en alquiler. Opciones de politica en América Latina y el Caribe, Washington, DC: Banco Interamericano de Desarrollo.

Bluestone, B., Stevenson, M. y Williams, R. (2008). The urban experience. Economics, society, and public policy. Oxford, Reino Unido: Oxford University Press. 
Bouillon, C. (ed.). (2012). Room for development. Housing markets in Latin America and the Caribbean. Nueva York, NY: Palgrave MacMillan.

Castro, J., Coulomb, R., León, P. y Puebla, C. (2006). Los desarrolladores privados y la vivienda de interés social. En R. Coulomb y M. Schteingart (coords.), Entre el Estado y el mercado. La vivienda en el México de hoy (pp. 445-476). Ciudad de México: Universidad Autónoma Metropolitana / Miguel Ángel Porrúa.

Celis, F. (2017). ¿Qué son y cómo funcionan las fibras? Forbes, 23 de agosto. Recuperado de https://www.forbes.com.mx/que-son-las-fibras/

Centro de Investigación y Documentación de la Casa y Sociedad Hipotecaria Federal. (2014). Estado actual de la vivienda en México 2014. Ciudad de México.

Comisión Económica para América Latina y el Caribe. (2018). CEPALSTAT. Bases de datos y publicaciones estadísticas. Recuperado de http://estadisticas.cepal.org/cepalstat/web_cepalstat/buscador.asp?idioma $=$ e\&string_busqueda=vivienda

Comisión Nacional de Vivienda. (2019). Registro de vivienda. Ciudad de México: Sistema Nacional de Información e Indicadores de Vivienda. Recuperado de http://sniiv.beta.conavi.gob.mx/cubo/registro_vivienda. aspx (consultado en enero de 2019).

Connolly, P. (2006). La demanda habitacional. En R. Coulomb y M. Schteingart (coords.), Entre el Estado y el mercado. La vivienda en el México de hoy (pp. 85-114). Ciudad de México: Universidad Autónoma Metropolitana / Miguel Ángel Porrúa.

Connolly, P. (2012). La urbanización irregular y el orden urbano en la Zona Metropolitana del Valle de México. En C. E. Salazar (coord.), Irregular. Suelo y mercado en América Latina (pp. 379-425). Ciudad de México: El Colegio de México, A.C.

Consejo Nacional de Evaluación de la Política de Desarrollo Social. (2017). Medición de la pobreza en México y en las entidades federativas 2016. Resumen ejecutivo. Ciudad de México.

Consejo Nacional de Evaluación de la Política de Desarrollo Social. (2019). Medición de la pobreza. Anexo estadístico de pobreza a nivel municipio 2010 y 2015. Ciudad de México. Recuperado de https://www.coneval. org.mx/Medicion/Paginas/AE_pobreza_municipal.aspx

Consejo Nacional de Población y Secretaría de Desarrollo Social. (2012). Catálogo Sistema Urbano Nacional 2012. Ciudad de México.

Coulomb, R. (2006). La vivienda en arrendamiento. En R. Coulomb y M. Schteingart (coords.), Entre el Estado y el mercado. La vivienda en el 
México de hoy (pp. 115-149). Ciudad de México: Universidad Autónoma Metropolitana / Miguel Ángel Porrúa.

Ferguson, C. E. y Gould, J. P. (1978). Teoría microeconómica. Ciudad de México: Fondo de Cultura Económica.

Fujita, M. (1989). Urban economic theory. Land use and city size. Cambridge, MA: Cambridge University Press.

García, M. J. (2017). El impacto de la Ley de Renta Congelada en la Ciudad de México (1942-2001). En A. Lira y E. Speckman Guerra (coords.), El mundo del derecho II. Instituciones, justicia y cultura jurídica (pp. 487-511). Ciudad de México: Universidad Nacional Autónoma de México, Instituto de Investigaciones Jurídicas / Escuela Libre de Derecho.

Garza, G. y Schteingart, M. (1978). La acción habitacional del Estado en México. Ciudad de México: El Colegio de México, A.C.

González, J. (2006). Dinámica reciente de la vivienda en renta en la Ciudad de México. Scripta Nova. Revista Electrónica de Geografía y Ciencias Sociales, 10(49). Recuperado de http://www.ub.edu/geocrit/sn/sn-21849.htm

INEGI (Instituto Nacional de Estadística y Geografía). (2018). Encuesta Nacional de Ingresos y Gastos de los Hogares. Aguascalientes, Ags., México.Recuperado dehttp://www.beta.inegi.org.mx/proyectos/enchogares/ regulares/enigh/tradicional/2002/default.html

INEGI (Instituto Nacional de Estadística y Geografía). (2018a). Encuesta Nacional de Vivienda (ENVI) 2014. Aguascalientes, Ags., México. Recuperado de http://www.beta.inegi.org.mx/proyectos/enchogares/ especiales/envi/

Isunza, G. (2010). Política de vivienda y movilidad en la Ciudad de México. Estudios Demográficos y Urbanos, 25(2), 277-316. Recuperado de https://estudiosdemograficosyurbanos.colmex.mx/index.php/edu/ article/view/1352/1345

Lesthaeghe, R. (2012). The unfolding story of the second demographic transition. Population and Development Review, 36(2), 211-251. Recuperado de https://onlinelibrary.wiley.com/doi/abs/10.1111/j.1728-4457. 2010.00328.x

Moctezuma Mendoza, V. (2016). El desplazamiento de lo posible: experiencia popular y gentrificación en el Centro Histórico de Ciudad de México. Revista de Ciencias Sociales. Íconos, 56, 83-102. Recuperado de https://dialnet.unirioja.es/servlet/articulo? codigo=5619719

Montoya, E. (2011). Hacia una vivienda de interés social sostenible en la ciudad de Tijuana. (Tesis de maestría, Universidad Politécnica de Ca- 
taluña, Barcelona). Recuperado de https://upcommons.upc.edu/handle/ 2099.1/9959

Núñez, B. (2007). Grandes desarrollos habitacionales en la Zona Metropolitana de Guadalajara. Espiral, 13(39), 111-137. Recuperado de http:// www.scielo.org.mx/pdf/espiral/v13n39/v13n39a4.pdf

Olivera, G. (2018). Continuidad de la urbanización informal en los espacios de pobreza metropolitanos, rémora del desarrollo y déficit de la política de vivienda: Cuernavaca, Mor., México. Territorios, 39, 97-133. Recuperado de http://www.scielo.org.co/pdf/terri/n39/0123-8418-terri39-00097.pdf

O’Sullivan, A. (2009). Urban economics, Boston, MA: McGraw-Hill International Edition.

Ortega, L. (2016). Autoconstrucción de vivienda, espacio y vida familiar en la Ciudad de México. Ciudad de México: Facultad Latinoamericana de Ciencias Sociales / Universidad Nacional Autónoma de México.

Patiño, L. (2006). El Fondo de Vivienda del Instituto de Seguridad y Servicios Sociales para los Trabajadores del Estado (FOVISSSTE). En R. Coulomb y M. Schteingart (coords.), Entre el Estado y el mercado. La vivienda en el México de hoy (pp. 279-317). Ciudad de México: Universidad Autónoma Metropolitana / Miguel Ángel Porrúa.

Pedrotti, C. (2016). Políticas habitacionales para los hogares urbanos de América Latina, de cara a Hábitat III. Economía, Sociedad y Territorio, 16(52), 795- 800. Recuperado de https://est.cmq.edu.mx/index. php/est/article/view/933/1215

Pérez Amador, J. (2016). Continuity and change of cohabitation in Mexico: Same as before or different anew. Demographic Research, 35(42), 1245-1258. Recuperado de https://www.demographic-research.org/ volumes/vol35/42/35-42.pdf

Puebla, C. (2006). El Instituto del Fondo Nacional de Vivienda para los Trabajadores (INFONAVIT). En R. Coulomb y M. Schteingart (coords.), Entre el Estado y el mercado. La vivienda en el México de hoy (pp. 193-238). Ciudad de México: Universidad Autónoma Metropolitana / Miguel Ángel Porrúa.

Quispe, J. (2005). El problema de la vivienda en Perú: retos y perspectivas. Revista Invi, 20(53), 20-44. Recuperado de http://www.redalyc.org/ articulo.oa? $\mathrm{id}=25805303$

Rossi, P. (1955). Why families move: A study in the social psychology of residential mobility. Glencoe, IL: Free Press. 
Salazar, C. E. (coord.). (2012). Irregular. Suelo y mercado en América Latina. Ciudad de México: El Colegio de México, A.C.

Salazar, C. E., Puebla, C., Ponce, G. y Flores, R. (2014). Alquiler y mercado del suelo en México. En A. Blanco, V. Fretes y A. Muñoz (eds.), Busco casa en arriendo. Promover el alquiler tiene sentido (pp. 291-334). Washington, DC: Banco Interamericano de Desarrollo.

Schteingart, M. (1989). Los productores del espacio habitable. Estado, empresa y sociedad en la Ciudad de México. Ciudad de México: El Colegio de México, A.C.

Schteingart, M. y Graizbord, B. (coords.). (1998). Vivienda y vida urbana en la Ciudad de México: la acción del Infonavit. Ciudad de México: El Colegio de México, A.C.

Secretaría de Desarrollo Agrario, Territorial y Urbano y Consejo Nacional de Población (2018). Sistema Urbano Nacional 2018. Ciudad de México.

Secretaría de Desarrollo Social, Consejo Nacional de Población e Instituto Nacional de Estadística y Geografía. (2012). Delimitación de las zonas metropolitanas de México 2010. Ciudad de México.

Sobrino, J. (2014). Evolución y determinantes de la pobreza de las principales ciudades de México, 1990-2010. Ciudad de México: Consejo de Evaluación de la Política de Desarrollo Social.

Sobrino, J. (2014a). Housing prices and submarkets in Mexico City: A hedonic assessment. Estudios Económicos, 29(1), 57-84. Recuperado de https://estudioseconomicos.colmex.mx/index.php/economicos/article/ view/74

Solís, P. (2016). De joven a adulto en familia: trayectorias de emancipación familiar en México. En M. L. Coubés, P. Solís y M. E. Zavala (coords.), Generaciones, cursos de vida y desigualdad social en México (pp. 193222). Ciudad de México: El Colegio de México, A.C.

Suárez, A. (2015). Valor del equipamiento habitacional en la Ciudad de México. En G. Garza (coord.), Valor de los medios de consumo colectivo en la Ciudad de México (pp. 73-159). Ciudad de México: El Colegio de México, A.C.

Topalov, C. (1979). La urbanización capitalista. Ciudad de México: Edicol. Torres, J. (2012). Estudio sobre el mercado de arrendamiento de vivienda en Colombia. (Nota técnica núm. IDB-TN-372). Nueva York, NY: Banco Interamericano de Desarrollo.

United Nations Human Settlements Programme. (2003). Rental housing: An essential option for the urban poor in developing countries. Nairobi, Kenia: UN-Habitat. 
Van Ommeren, J. y Graaf-de Zijl, M. (2013). Estimating household demand for housing attributes in rent-controlled markets. Journal of Housing Economics, 22(1), 11-19. Recuperado de https://research.vu.nl/en/ publications/estimating-household-demand-for-housing-attributesin-rent-contro

Ward, P., Jiménez, E. y Di Virgilio, M. (2015). Politicas habitacionales para los hogares urbanos de América Latina, de cara a Hábitat III. Londres, Inglaterra: Routledge.

Ziccardi, A. y Cravacuore, D. (2017). Introducción. En A. Ziccardi y D. Cravacuore (coords.), Los gobiernos locales y las politicas de vivienda en México y América Latina (pp. 9-15). Ciudad de México: Universidad Nacional Autónoma de México / Universidad Nacional de Quilmes / Universidad Nacional de General Sarmiento.

\section{Acerca del autor}

Jaime Sobrino es profesor-investigador del Centro de Estudios Demográficos, Urbanos y Ambientales (CEDUA) de El Colegio de México, A.C. Es doctor en Urbanismo por la Universidad Nacional Autónoma de México (UNAM) y maestro en Desarrollo Urbano por El Colegio de México, A.C. Sus líneas de investigación son: $i$ ) competitividad urbana; ii) expansión metropolitana; iii) mercado urbano de vivienda; y iv) migración interna. Es autor y coautor de libros, artículos y capítulos en temas relacionados con economía urbana y regional. En los programas docentes del CEDUA es profesor de las materias Economía urbana, Geografía económica, Análisis espacial y Estadística. Es profesor por asignatura en la UNAM de la materia Geografía urbana. Fue profesor visitante en University of East Anglia, Reino Unido (2003) y en Bucknell University, Estados Unidos (2012-2013). Es miembro de la Sociedad Mexicana de Demografía y de Global Urban Competitiveness. Pertenece al Sistema Nacional de Investigadores, nivel III. ORCID: https://orcid.org/0000-0002-2788-7209

Entre sus publicaciones se encuentran:

Giorguli, S. y Sobrino, J. (eds.). (2020). Dinámica demográfica de México en el siglo XXI, tomos 1 y 2. Ciudad de México: El Colegio de México, A.C.

Sobrino, J. y Ugalde, V. (eds.). (2019). Desarrollo urbano y metropolitano en México. Ciudad de México: El Colegio de México, A.C. 
Sobrino, J. (2014). Housing prices and submarkets in Mexico City: A hedonic assessment. Estudios Económicos, 29(1), 57-84. Recuperado de https:/estudioseconomicos.colmex.mx/index.php/economicos/article/ view/74/75

Recepción: 9 de enero de 2019. Aceptación: 23 de mayo de 2019. 